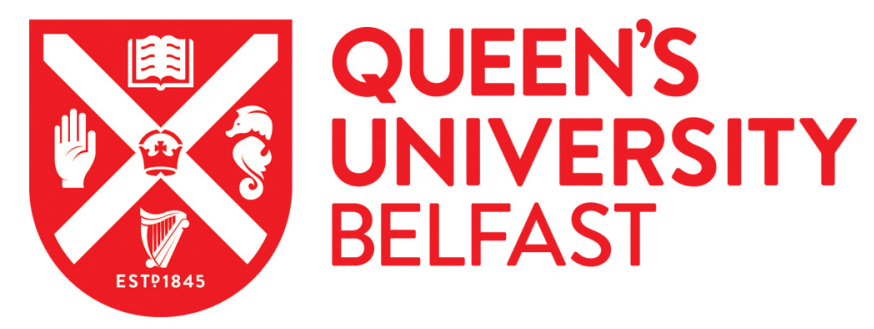

\title{
Experimental application of digital image correlation for the tensile characterization of basalt FRCM composites
}

D'Anna, J., Amato, G., Chen, J. F., Minafò, G., \& La Mendola, L. (2020). Experimental application of digital image correlation for the tensile characterization of basalt FRCM composites. Construction and Building Materials, 271, [121770]. https://doi.org/10.1016/j.conbuildmat.2020.121770

Published in:

Construction and Building Materials

Document Version:

Peer reviewed version

Queen's University Belfast - Research Portal:

Link to publication record in Queen's University Belfast Research Portal

Publisher rights

Copyright 2020 Elsevier Ltd

This manuscript is distributed under a Creative Commons Attribution-NonCommercial-NoDerivs License

(https://creativecommons.org/licenses/by-nc-nd/4.0/), which permits distribution and reproduction for non-commercial purposes, provided the author and source are cited

\section{General rights}

Copyright for the publications made accessible via the Queen's University Belfast Research Portal is retained by the author(s) and / or other copyright owners and it is a condition of accessing these publications that users recognise and abide by the legal requirements associated with these rights.

Take down policy

The Research Portal is Queen's institutional repository that provides access to Queen's research output. Every effort has been made to ensure that content in the Research Portal does not infringe any person's rights, or applicable UK laws. If you discover content in the Research Portal that you believe breaches copyright or violates any law, please contact openaccess@qub.ac.uk. 


\title{
Experimental application of Digital Image Correlation for the tensile characterization of basalt FRCM composites
}

Jennifer D’Anna*1, Giuseppina Amato ${ }^{2}$, Jian Fei Chen ${ }^{3}$, Giovanni Minafò ${ }^{1}$, Lidia La Mendola ${ }^{1}$

${ }^{1}$ Università degli Studi di Palermo, Dipartimento di Ingegneria, Viale delle Scienze, 90128 Palermo, Italy.

${ }^{2}$ Queen's University Belfast, School of Natural and Built Environment, David Keir Building, Stranmillis road, BT9 $5 A G$ Belfast, United Kingdom

${ }^{3}$ Department of Ocean Science and Engineering, Southern University of Science and Technology (China)

*Corresponding author jennifer.danna@unipa.it

\begin{abstract}
Composites made with inorganic matrix, namely fibre reinforced cementitious mortar (FRCM) composites are becoming widespread as strengthening materials for existing masonry structures. These composites are made of a dry grid of fibres embedded in an inorganic matrix. FRCMs can be considered a valid alternative to traditional organic composites such as Fibre Reinforced Polymers (FRPs) because of their better compatibility with the masonry support. This work presents an experimental study for the tensile characterization of a basalt fibre reinforced cementitious matrix (BFRCM) composite. Tensile tests were carried out on coupons reinforced with one, two or three layers of grid to investigate the influence of the reinforcement on the load-strain and stress-strain response of the composite. The basalt grid and cementitious mortar matrix were also tested in order to compare the mechanical properties of the constituent materials to the response of the composite. The digital image correlation (DIC) technique was used to check in-plane and out-of-plane bending effect, to measure the crack opening and to analyse the crack pattern evolution and failure modes.
\end{abstract}

Keywords: Basalt grid, FRCM, Tensile tests, Reinforcement ratio, Digital Image Correlation (DIC), Crack pattern 


\section{Introduction}

Fabric reinforced cementitious mortar (FRCM) composites are largely used nowadays for strengthening concrete and masonry structures, especially when specific preservation criteria need to be fulfilled. Fibre reinforced polymers (FRP) materials externally bonded by means of epoxy adhesive were deeply investigated and adopted for retrofitting applications in the last two decades. However, the organic nature of polymer-based composites causes some compatibility drawbacks, particularly when FRPs are used for strengthening masonry structures. In the effort to overcome these issues, growing attention has been paid to composites as the inorganic matrix is able to guarantee higher breathability and compatibility to the substrate and higher resistance to fire and high temperatures.

In the last years many experimental studies have been carried out to investigate the tensile behaviour of these systems [1][2][3] and different International Standard were recently published [4]. Cement-based composites show a complex mechanical behaviour in tension, which is affected not only by the properties of the fabric and matrix but also by the bond strength at the interface between these two components, as demonstrated by many investigations [7][8]. The large number of available textiles and mortars results in a wide variability in terms of mechanical behaviour, tensile strength capacity, bond performance with the substrate and expected failure modes [9].

In most experimental tests available in the literature, traditional measurement systems, i.e. displacement transducers and strain gauges, were used to acquire strain data. However, it is worth to note that these monitoring systems showed to be not always adequate for FRCMs: the strain gauges are able to measure only local values, while the reliability of displacement measures obtained from the use of transducers is strongly related to the choice of their position that depends on the cracking pattern, unknown before the test. For these reasons, in some cases, traditional instrumentations were complemented or substituted by innovative monitoring techniques, such as digital image correlation (DIC).

Bilotta et al. [10] presented the results of tensile tests on different types of FRCM systems. The outcomes were discussed in terms of failure modes and the tests were analysed through the DIC technique, which showed to be particularly useful to observe the behaviour of the specimen without knowing a priori the final crack pattern. The DIC technique was used by Caggegi et al.[11] to carried out an experimental study of basalt FRCM system. Four series of specimens, strengthened by different reinforcement ratios and prepared using different kinds of mortar, were tested under tension. DIC allowed a deep description of the displacement fields and the crack pattern during the tests. The comparison between different results underlined the influence of different investigated parameters on the behaviour of the FRCM system. In Tekieli et al. [12], DIC technique was used in tensile tests on composites including different textiles and matrices. Results from two DIC software programs were validated by comparison with displacement 
transducers. The use of DIC allowed achieving additional information on damage pattern, namely crack location and width, and also offered the opportunity of selecting different measurements points after testing.

In D'Antino and Papanicolaou [13], the mechanical properties of four different FRCM composites were investigated, using different tensile test setups. Longitudinal displacements were measured using traditional transducers and DIC method. DIC measurements allowed for proposing two criteria to assess the reliability of results obtained with tensile tests of FRCM composites. Tensile characterization of FRCM coupons with continuous and overlapped glass fabrics were performed by Donnini et al. [14]. Deformations and failure modes of FRCM specimens were investigated by using DIC technique and compared with numerical simulations.

Despite the capability of the DIC technique for measurement applications of direct tensile tests on FRCM strips, few studies are currently available on the subject and fewer are performed on basalt FRCM. Additionally, the potential of DIC for the full field analysis of displacements and strains of FRCM coupons has not been fully exploited yet. This includes the progressive formation of the cracks and the evolution of the crack pattern up to failure. The goal of this paper is to give a complete and deep insight into the mechanical response of basalt FRCMs and to underline the full potential of DIC in order to reach this aim. The current work also points out the advantageous application of DIC when two cameras are used to monitor in-plane and out-of-plane bending moments, which can affect the results of tensile tests. This is a novel contribution. Moreover, most studies on FRCM tensile characterization address single-ply fabric reinforced composites, while few works study the influence of higher number of grid layers [15][16][17], which is very important to be investigated since strengthening applications usually involve multi-ply FRCM composites. In this respect, the assumption of a directly proportional relationship between FRCM tensile capacity and the number of textile layers cannot be taken for granted.

This work presents the outcomes of an experimental study for the tensile characterization of basalt FRCM (BFRCM) coupons, performed using the DIC. Specimens reinforced with one, two or three grid layers were tested in order to investigate the influence of the basalt grid reinforcement on the tensile behaviour of the composite coupons. The basalt grid and mortar matrix were also tested in order to relate the mechanical properties of constituent materials to the behaviour of the composite. The DIC technique was used to carry out different analyses by measuring strains along defined gauge lengths or in the form of continuous field analysis on the surface of the specimens. The possibility of choosing different virtual extensometers allowed investigating on the possible presence of defects affecting the results. DIC full field analyses allowed highlighting differences in the strain and crack distribution occurring in specimens strengthened with different reinforcement ratios and deeply analysing the crack evolution during tests, up to failure. 


\section{Experimental programme}

A total of fourteen BFRCM composite coupons, manufactured using different reinforcement ratios, were tested in this study: eight specimens made with one grid layer, five using two layers and one single specimen made with three layers. It should be noted that the same number of specimens was planned to be tested for each investigated series, but some coupons were damaged during the preparation or testing operations.

Specimens were named following the designation SPX_YL, where SP means "specimen", X indicates the specimen number, $\mathrm{Y}$ is used to designate the number of reinforcing layers (1, 2 or 3), L means "layer".

\subsection{Basalt grid and mortar matrix}

The grid used as composite reinforcement is a primed alkali-resistant basalt fibre bidirectional grid. The mechanical properties of the grid along the warp direction provided by the manufacturer are reported on Table 1 .

Table 1: Material properties from manufacturer

\begin{tabular}{|c|c|c|c|c|c|c|c|}
\hline & $\begin{array}{c}\text { Unit } \\
\text { weight }\end{array}$ & Mesh size & Density & $\begin{array}{c}\text { Tensile } \\
\text { strength }\end{array}$ & $\begin{array}{c}\text { Elastic } \\
\text { modulus }\end{array}$ & $\begin{array}{l}\text { Equivalent } \\
\text { thickness }\end{array}$ & $\begin{array}{c}\text { Elongation at } \\
\text { failure }\end{array}$ \\
\hline $\begin{array}{c}\text { Basalt } \\
\text { grid }\end{array}$ & $250 \mathrm{~g} / \mathrm{m}^{2}$ & $6 \times 6 \mathrm{~mm}$ & $2.75 \mathrm{~g} / \mathrm{cm}^{3}$ & $60 \mathrm{kN} / \mathrm{m}$ & $89 \mathrm{GPa}$ & $0.039 \mathrm{~mm}$ & $1.8 \%$ \\
\hline & \multicolumn{3}{|c|}{ Flexural strength } & \multicolumn{2}{|c|}{ Compressive strength } & \multicolumn{2}{|c|}{ Elastic modulus } \\
\hline Mortar & \multicolumn{3}{|c|}{$8 \mathrm{MPa}$} & \multicolumn{2}{|c|}{$25 \mathrm{MPa}$} & \multicolumn{2}{|c|}{$10 \mathrm{GPa}$} \\
\hline
\end{tabular}

Monotonic tensile tests of basalt grid strips were carried out in agreement to ISO 13934-1 [18] to define the mechanical characteristics of the grid. Twenty-one strips with dimension 260x13.5 mm were tested, twelve along the warp and twelve along the weft direction. Aluminium tabs, $80 \mathrm{~mm}$ long, $2 \mathrm{~mm}$ thick, were glued at the ends of the strips to guarantee a uniform stress distribution (Fig. 1). The tabs were gripped over a length of $50 \mathrm{~mm}$ and were longer than gripping length in order to avoid stress concentration at the transition section from machine clamps to specimen.

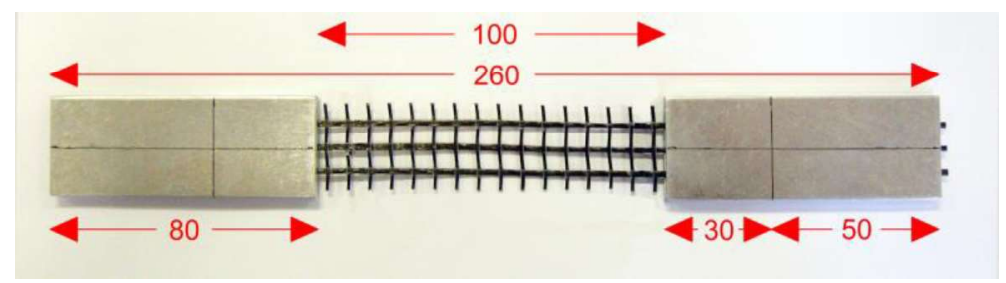

Fig. 1 Basalt grid sample before testing 
The tests were carried out using a $100 \mathrm{kN}$ universal machine in displacement control mode at a loading rate of

$2 \mathrm{~mm} / \mathrm{min}$. The specimens were lit from behind and displacements were recorded using a video-extensometer (Fig. 2a) able to track liner targets attached to the strip over a gauge length of $80 \mathrm{~mm}$ (Fig. 2b).

The video-extensometer is a contact-free measurement system for high-resolution tensile and bending strain tests for nearly all different types of materials. This device can measure strains or displacements between two or more assigned markers. The apparatus is connected to a computer which stores and analyses the data using a suitable software. The images taken from the video-extensometer are processed directly during testing, based on the DIC software provided with the instrument. The video-extensometer must be supported by an illumination source, either on the front or on the back of the specimen (front light or a back light method), and by markers placed on the specimen. Different kinds of markers can be used to achieve an intense light-dark-contrast and therefore increase the accuracy and reduce signal noise. In general, the greater the contrast the more consistent the results obtained. Regarding tensile tests on basalt grid, the best setup was found to be the one involving linear markers and the rear illumination method.

The grid test results are reported in the Experimental Results section.
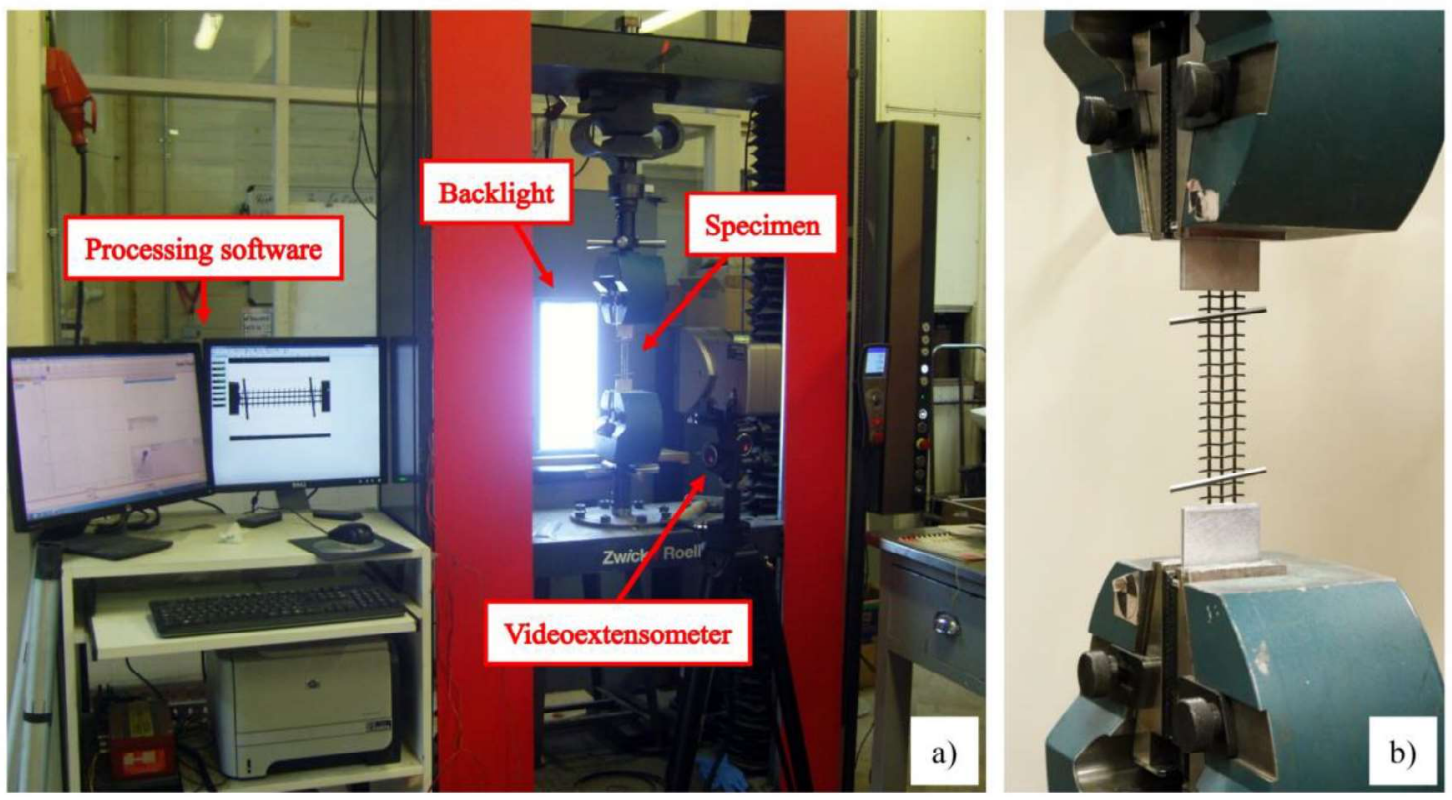

Fig. 2 Tensile test on basalt gird: a) test setup; b) specimen provided with linear target for DIC

The mortar used as FRCM matrix is a two-component, high-strength cement-based mix made of hydraulic natural lime, sand, special additives, polymers reinforced with short glass fibres. The mechanical characteristics of the mortar provided by the manufacturer are given in Table 1 . 
Three point bending tests were carried out on six 40x40x160 mm prisms according to EN 1015-11 [19]. Before

testing, the surface of the specimens was painted with a high-contrast texturing effect, using white paint with black speckle pattern, to carry out a strain field analysis by DIC.

\subsection{BFRCM coupons}

\subsubsection{Preparation}

Fourteen BFRCM composite specimens were manufactured using different reinforcement ratios.

The coupons were cut from large 500x500 mm slabs prepared in wood formworks (Fig. 3a) in agreement with AC434 American Standard [4]. The specimen dimensions were selected based on published research and existing regulations [4][5][20]. All composite samples had 40x8 mm cross sectional area and length of $400 \mathrm{~mm}$ (Fig. 4).
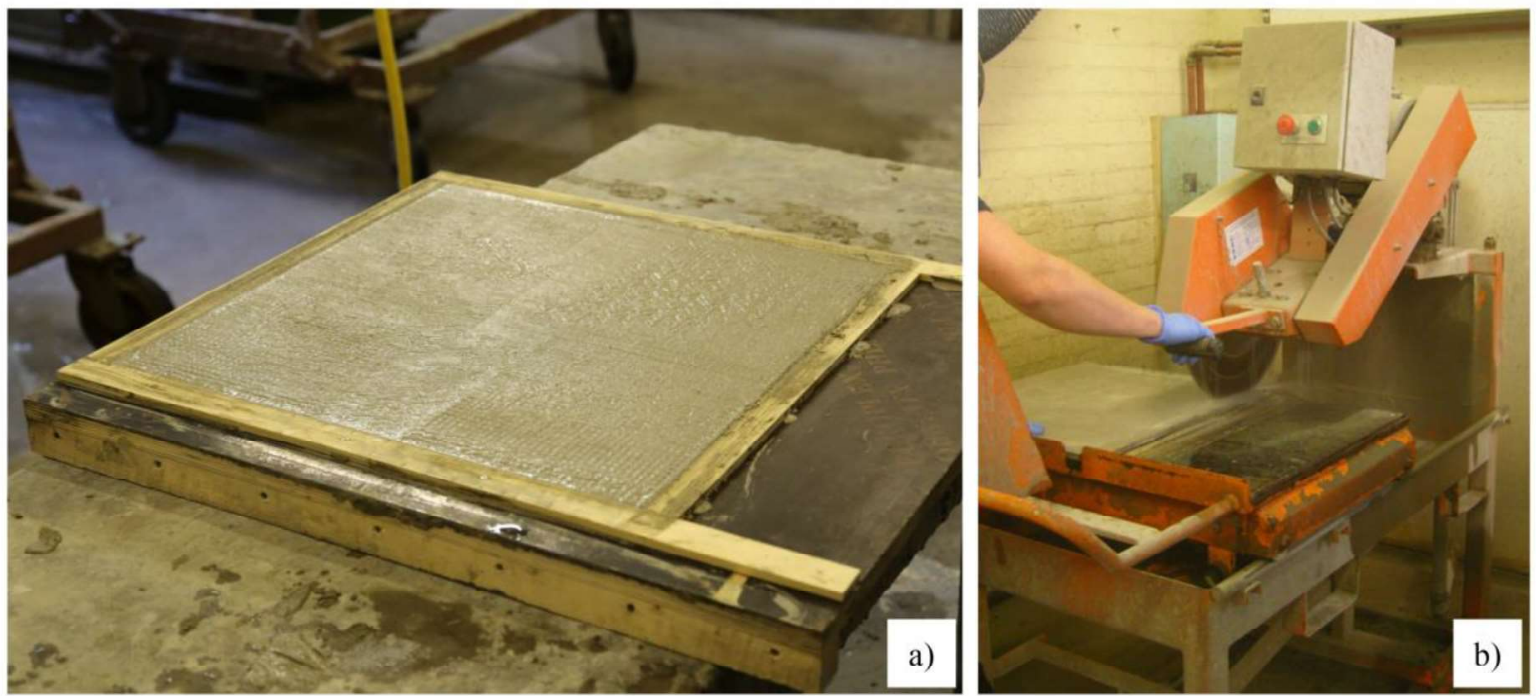

Fig. 3 Manufacturing of BFRCM coupons: a) composite slab; b) cutting of composite specimens

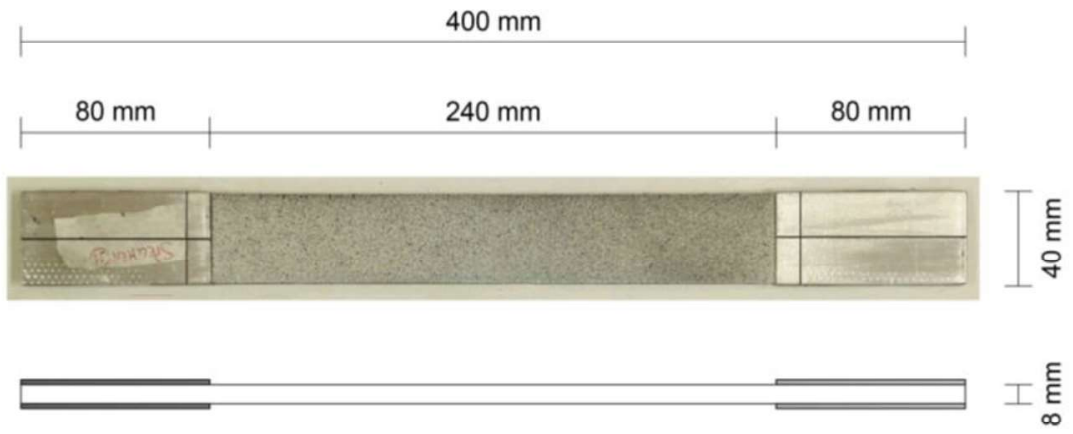

Fig. 4 Photo of BFRCM coupon showing aluminium tabs, speckle and size 
The BFRCM slabs were manufactured using the manual wet lay-up technique. The total thickness of the mortar was the same for all series. In the case of one-layer reinforced specimens, one basalt ply was positioned between two 4 mm thick mortar layers. For the specimens reinforced with two or three layers, the mortar layers were about 2 or $3 \mathrm{~mm}$.

After casting, the large slabs were cured in a saturated atmosphere $\left(20^{\circ} \mathrm{C}\right.$ and $70 \%$ relative humidity) for more than one month. In order to avoid differential shrinkage which could cause a curvature of the panel and bending problems during testing, the slabs were covered with wet drenched gunny cloths and plastic sheets. The panels were then demoulded and the composite coupons were cut using a circular wet saw (Fig. 3b). The specimens were then stored in laboratory conditions till the test day.

Aluminium tabs were glued on the edges of the coupons to reduce local stress concentration on the gripping area and to avoid the premature damage of the specimens. The front side and the thickness side of the specimens were painted with a high-contrast texturing effect using white paint with black speckle pattern to enable for contactless measurement readings during testing with the use of DIC (Fig. 4).

In the case of specimens reinforced with one basalt grid layer, the ends of the coupons were over-reinforced each one with two additional layers of $150 \times 40 \mathrm{~mm}$ textile, in order to promote the failure of the samples in their $100 \mathrm{~mm}$ middle portion (Fig. 5). Additional reinforcements at the extremity were not used for specimens reinforced with two and three layers because of the difficulty of placing many layers inside such a small thickness.

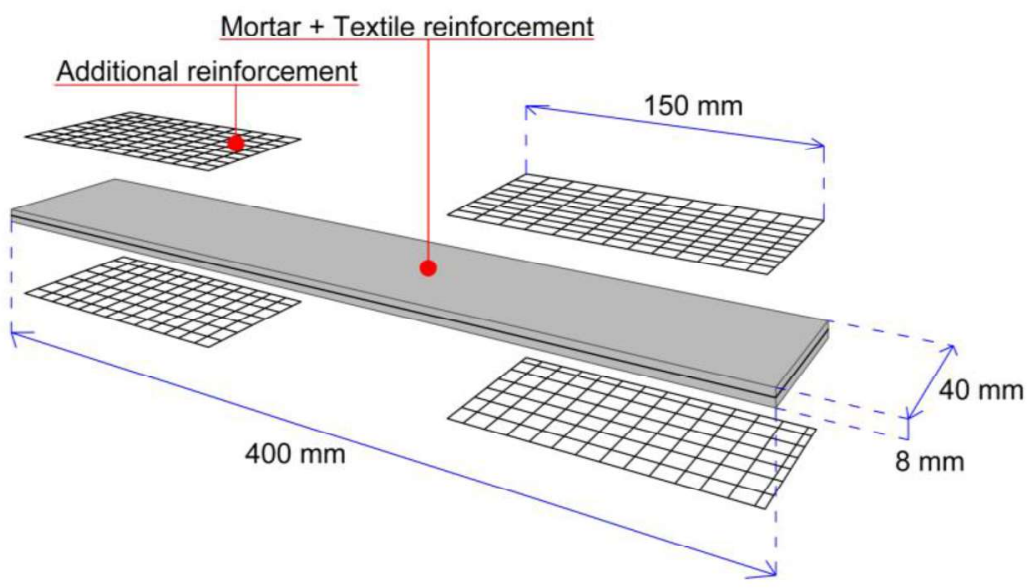

Fig. 5 Additional reinforcement in composite specimens strengthened with one basalt grid layer

\subsubsection{Test setup and DIC measurements}

The tensile monotonic tests were carried out using a $100 \mathrm{kN}$ universal testing machine, in displacement control mode with a loading rate of $0.2 \mathrm{~mm} / \mathrm{min}$ (Fig. 6), based on existing standards [4][5][20]. 

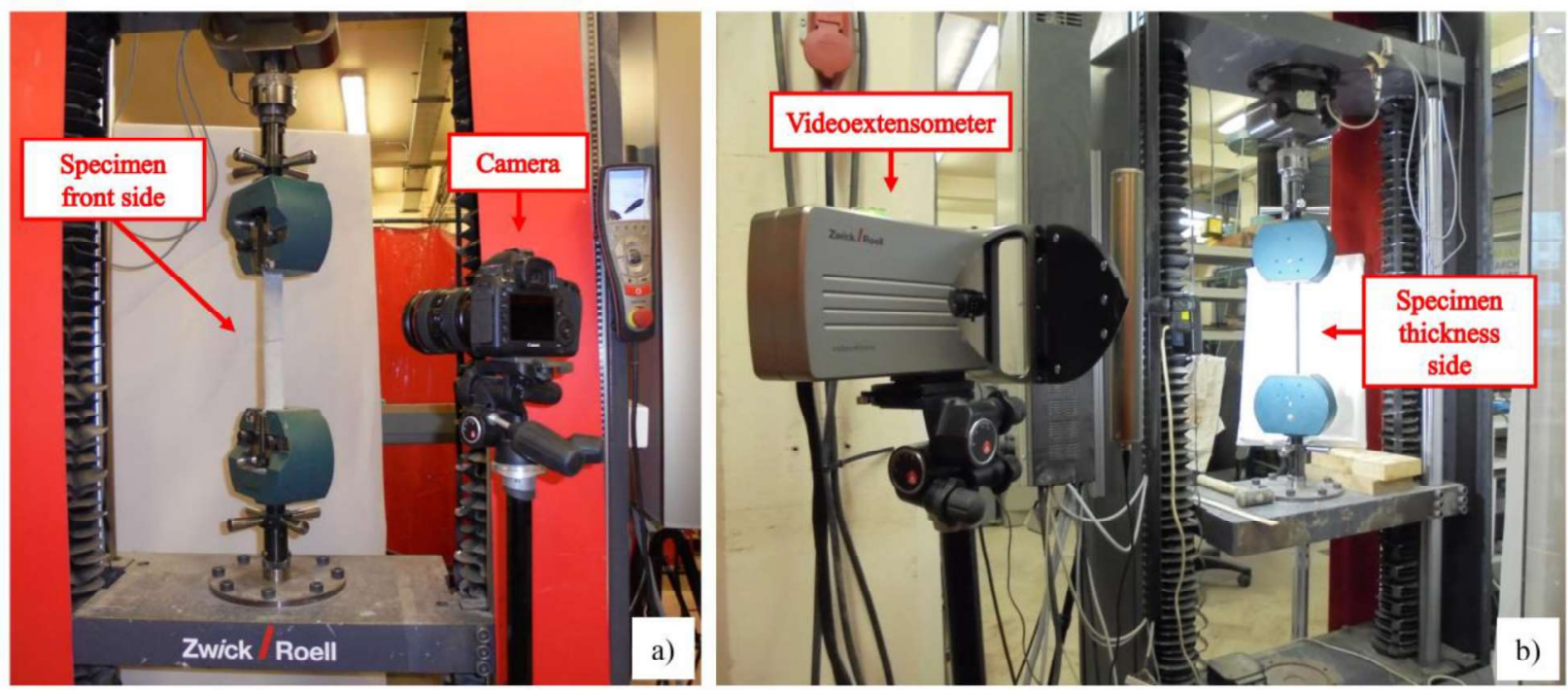

Fig. 6 Setup for tensile test on composite coupon: a) hight-resolution camera; b) videoextensometer

The strain field over the surface of the specimens was obtained from DIC measurements. Fig. 6 provides a view of the test setup. The photos were taken with a 22.3 Megapixel camera, positioned in front of the testing machine, with the lens direct towards the centre of the coupons and in perpendicular position in respect to the specimen surface (Fig. 6a). The entire coupon surface was recorded. A light source of constant luminosity was used to maintain consistency in the measurements. In addition, the videoextensometer and an auxiliary front light were used to monitor the strain field along the thickness of the specimens (Fig. 6b). This was done as geometrical imperfections such as non-symmetric distribution of reinforcement in the thickness or non-perfect planarity of the sample can cause different opening of cracks on the front and back surface.

The frame rates of camera and videoextensometer were set to $2 / \mathrm{s}$ and $1 / \mathrm{s}$ respectively. Resolution of the photos was $12 \mathrm{pixel} / \mathrm{mm}$ for the camera and $9 \mathrm{pixel} / \mathrm{mm}$ for the videoextensometer.

The software GOM Correlate [21] was used to carry out the DIC analysis. GOM Correlate gives the displacement/strain field at each loading step by defining square-shaped subzones, called "facets", in the initial image and tracking these subzones in subsequent images. The facets were defined over the random speckle pattern sprayed on the sample surface, which facilitated the definition of a grey level distribution sufficient to differentiate the subzones. A facet size of 20 pixels and a spacing of 18 pixels (point distance) (for full field analysis) were defined to accommodate both a good resolution and computational viability. A standard analysis, as defined by the software, was carried out. To minimise accumulation of errors [10] images from each loading step were compared to a reference image defined at step 1. 
The DIC analysis was carried out with two aims: to measure strain on virtual extensometers defined on each coupon and to record the crack pattern evolution during the test (continuous field analysis). Each virtual extensometer was defined by a couple of facets on the surface of the coupons. Three virtual strain extensometers were defined on onelayer specimens and on specimens with higher reinforcement ratio, as shown on Fig. 7. This was to check possible inplane bending effects. A gauge length of $240 \mathrm{~mm}$ was defined for two and three-layer specimens and a length of $100 \mathrm{~mm}$ for one-layer specimens due to the additional reinforcing layers at the ends of the coupon for this series (see Fig. 5).

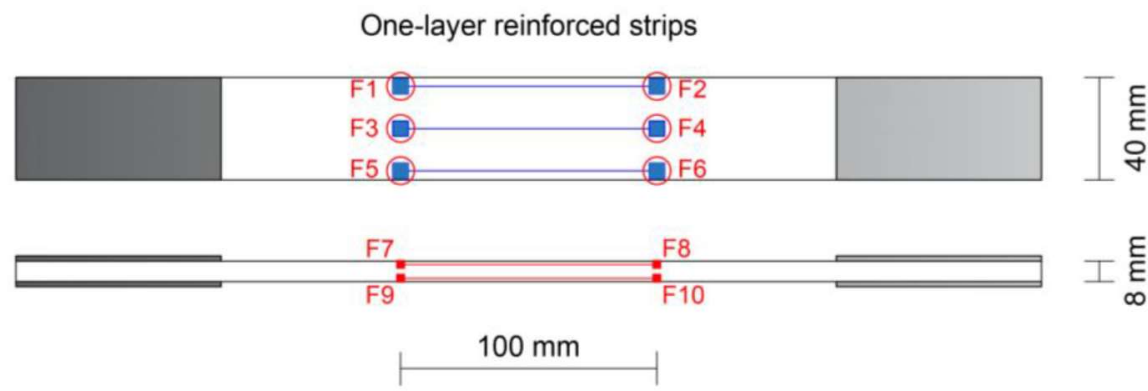

Two and three-layer reinforced strips

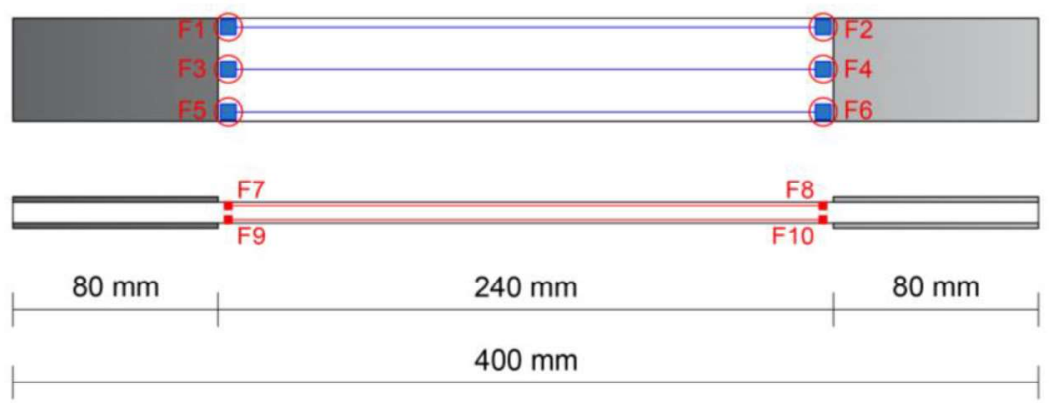

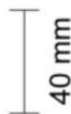

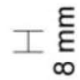

Fig. 7 Position of virtual extensometers on the front and side surfaces

Additional virtual extensometers, with the same gauge length as above, were defined on the thickness of the BFRCM coupons, in order to check possible out-of-plane bending effects, see Fig. 7.

A monitoring area was defined for the strain/displacement continuous field analysis. In this case facets were placed homogeneously over a $150 \mathrm{~mm}$ long region for one-layer specimens and over the whole surface for the remaining coupons, see Fig. 8. 


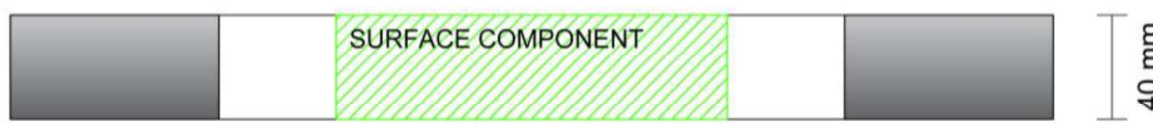

$150 \mathrm{~mm}$

Two and three-layer reinforced strips

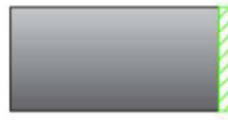

SURFACE COMPONENT

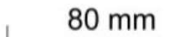

$240 \mathrm{~mm}$

$80 \mathrm{~mm}$
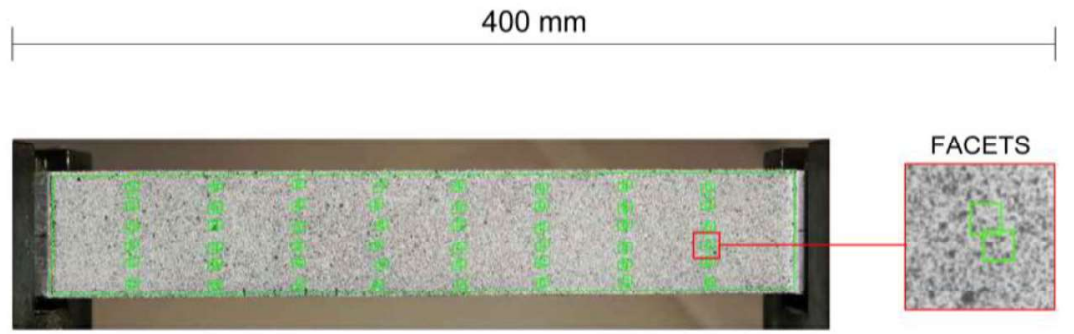

Fig. 8 Full-field analysis: surface components and distribution of facets

\section{Experimental results}

\subsection{Grid and matrix}

The experimental stress-strain curves of the basalt grid specimens along the warp and the weft directions are plotted in Fig. 9. The average and coefficient of variation (COV) values of the tensile strength, strain and elastic modulus are reported on Table 2 .

Due to the discrete distribution of fibres along the width of the strips, the stress values were evaluated considering a cross sectional area of grid calculated as the equivalent thickness $(0.039 \mathrm{~mm})$ multiplied by a width equal to the number of yarns multiplied by the mesh size $(3 \times 6 \mathrm{~mm})$. 
Table 2: Grid and mortar average results

\begin{tabular}{|c|c|c|c|c|c|c|}
\hline \multicolumn{6}{|c|}{ BASALT GRID } & \multirow{3}{*}{$\begin{array}{c}\text { MORTAR } \\
\\
\begin{array}{c}\text { Av. Flexural } \\
\text { strength [MPa] } \\
\text { and }(\mathrm{COV})\end{array}\end{array}$} \\
\hline \multicolumn{3}{|c|}{ WARP DIRECTION } & \multicolumn{3}{|c|}{ WEFT DIRECTION } & \\
\hline $\begin{array}{c}\text { Av. Tensile } \\
\text { strength [MPa] } \\
\text { and }(\mathrm{COV})\end{array}$ & $\begin{array}{c}\text { Av. Tensile } \\
\text { strain [\%] } \\
\text { and }(\mathrm{COV})\end{array}$ & $\begin{array}{c}\text { Av. Elastic } \\
\text { modulus [GPa] } \\
\text { and }(\mathrm{COV})\end{array}$ & $\begin{array}{l}\text { Av. Tensile } \\
\text { strength } \\
\text { [MPa] and } \\
\text { (COV) }\end{array}$ & $\begin{array}{l}\text { Av. Tensile } \\
\text { strain [\%] } \\
\text { and }(\mathrm{COV})\end{array}$ & $\begin{array}{c}\text { Av. Elastic } \\
\text { modulus [GPa] } \\
\text { and }(\mathrm{COV})\end{array}$ & \\
\hline 2045 & 2.55 & 81.91 & 1983 & 2.40 & 81.88 & 7.18 \\
\hline$(10.55 \%)$ & $(8.21 \%)$ & $(3.48 \%)$ & $(7.80 \%)$ & $(12.05 \%)$ & $(4.60 \%)$ & $(2.80 \%)$ \\
\hline
\end{tabular}

The tensile curves of specimens in the warp (Fig. 9a) and weft (Fig. 9b) directions show a linear trend characterized by the brittle failure of the grid. Fig. 10 shows some of the basalt specimens after failure. As it can be seen in the photo, the failure of the samples was characterized by the tensile rupture of some or all basalt rovings in the strip width, in the middle of the strips or close to the gripping zone. Telescopic failure was observed between external coated fibres and internal fibres of basalt yarns. Slipping inside the gripping area was not observed.

The average peak stress and strain, averaged over twelve samples in warp direction, were $2045 \mathrm{MPa}$ and $2.6 \%$ respectively; the elastic modulus was $82 \mathrm{GPa}$. The values obtained from the specimens tested along the weft direction are $1983 \mathrm{MPa}, 2.4 \%$ and $82 \mathrm{GPa}$ respectively for average strength, average strain and average Young's modulus.

It should be noted that the experimental tensile strain of the fabric along the warp direction $(2.55 \%)$ was larger than the one provided by the manufacturer (1.8\%). Usually, data from producer are conservative. Moreover, it should be noted that there is an important size effect, since the smaller the strip width, the higher the strength. This is mainly due to the geometrical misalignment of the yarns and other geometrical imperfections and also to possible misalignments during tensile tests.

The average flexural strength of the three point bending tests $(7.18 \mathrm{MPa})$ carried out on the matrix samples is reported on Table 2 along with the COV values. 

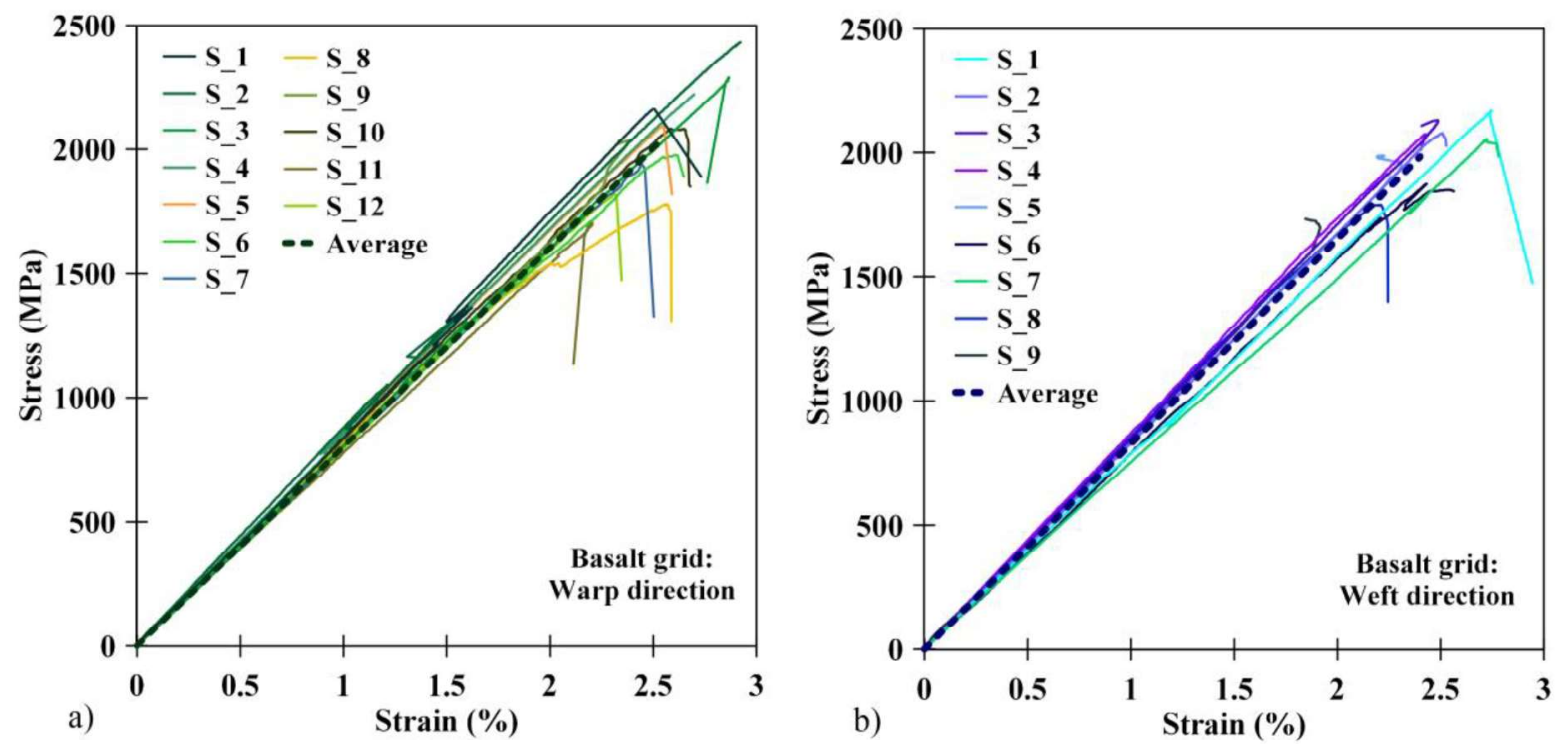

Fig. 9 Stress-strain curves for basalt grid: a) warp direction; b) weft direction

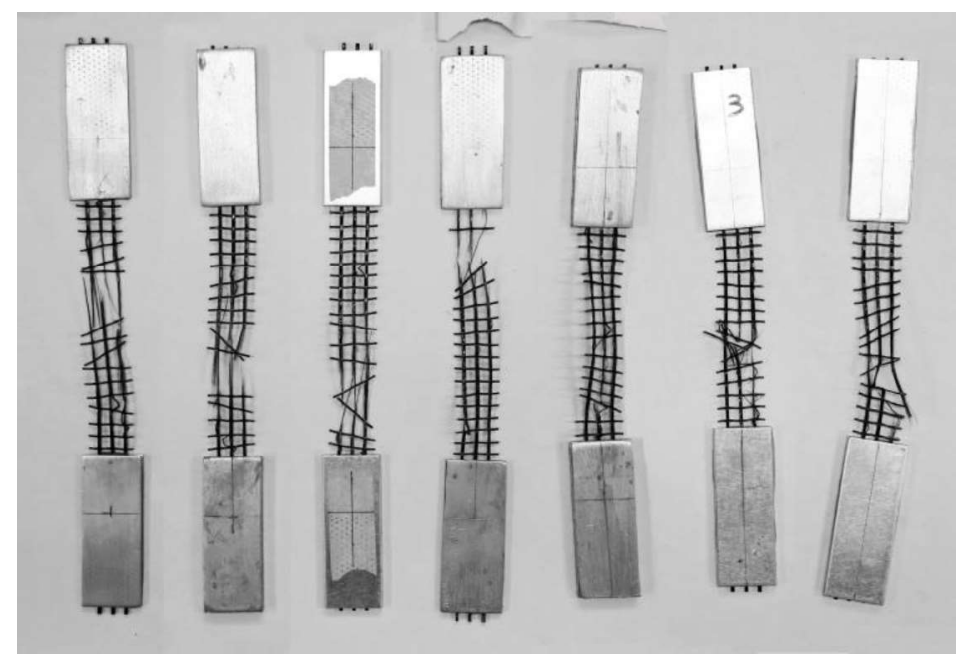

Fig. 10 Basalt grid strips at failure

\subsection{Composite coupons}

\subsubsection{Results from virtual extensometer}

The tensile stress-strain curves of three specimens reinforced with one layer of basalt grid are plotted on Fig. 11.

The graph shows, for each specimen, the measurements of the three virtual extensometers placed on the front side (Fig. 11 a). The scatter of the strains at peak stress ranges from $0.44 \%$ to $4 \%$ and confirms the absence of significant bending effects in the plane of the specimen. 


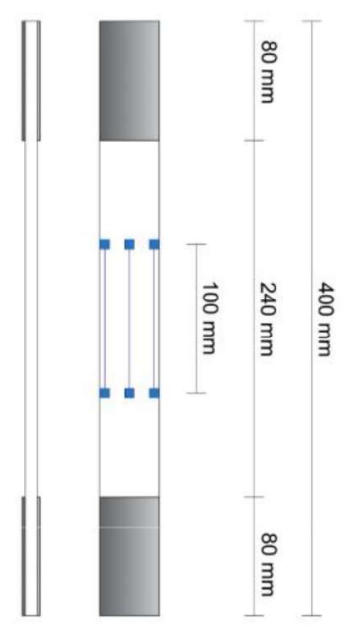

a) $8 \mathrm{~mm} \quad 40 \mathrm{~mm}$

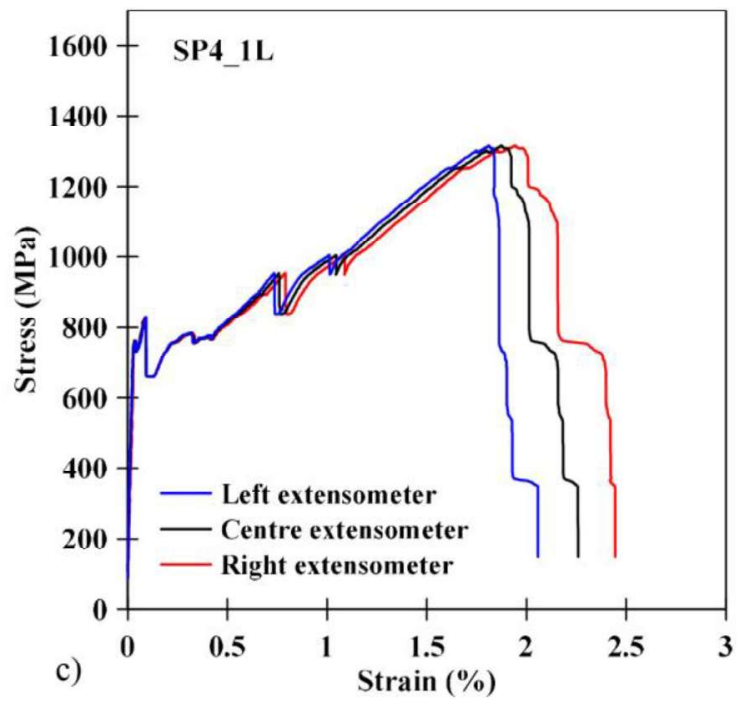

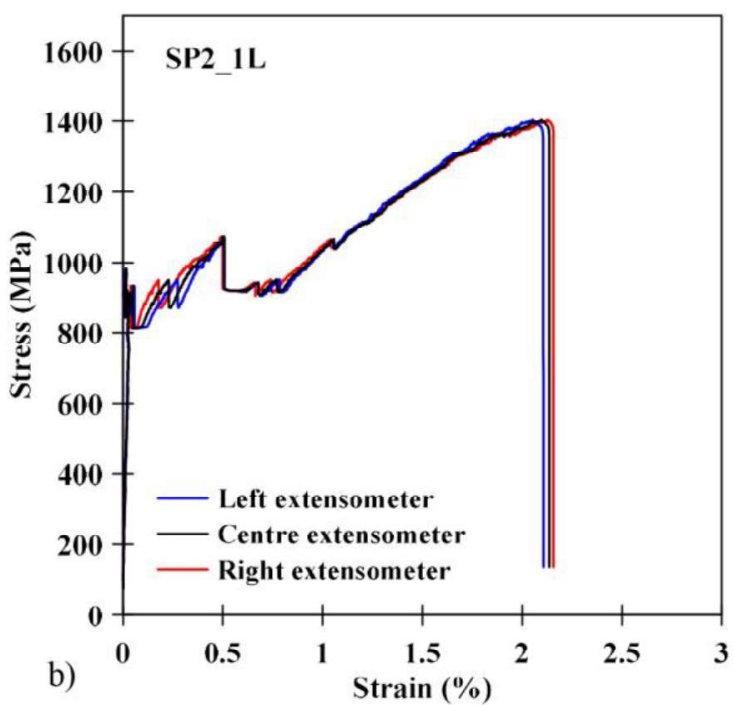

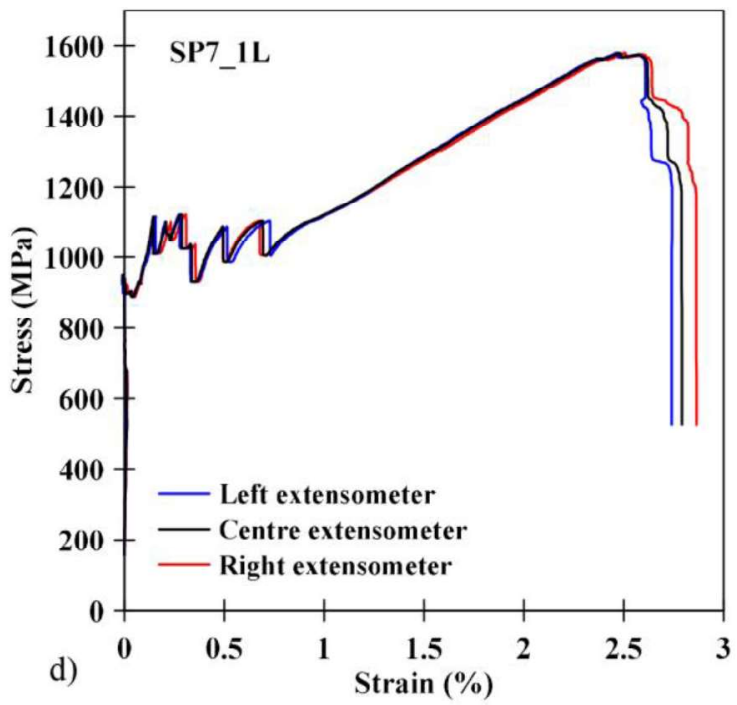

Fig. 11 Stress-strain curves obtained from central and side virtual extensometers in one-layer reinforced specimens: a) position of virtual extensometers; b) specimen SP2_1L; c) specimen SP4_1L; d) specimen SP7_1L

Similar results were obtained for specimens reinforced with two and three basalt grid layers. Only the readings of specimen SP4_2L and SP5_2L were affected by a moderate scatter (14\%). This is due to the fact that, at the end of the cracking development stage, these specimens were affected by slight slipping inside the clamping area with a consequent load redistribution over the cross-section. The lower peak stress of these two samples compared to specimens SP1_2L and SP2_2L could be due to the in-plane bending effect during the test.

Regarding possible out-of-plane bending effects, strains from virtual extensometers on the side surface are plotted in

Fig. 12, for SP4_2L and SP1_3L specimens, with two and three layers respectively. In this case, the results obtained from the readings of the two extensometers for each sample are very consistent, underlining a uniform crack development along the front and back surface of the specimens and the absence of important defects causing out-of- 
plane curvature of the samples. The scatter of the strains at peak stress ranges from $1.16 \%$ to $1.58 \%$.

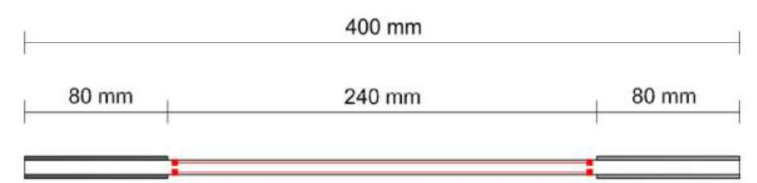

a)
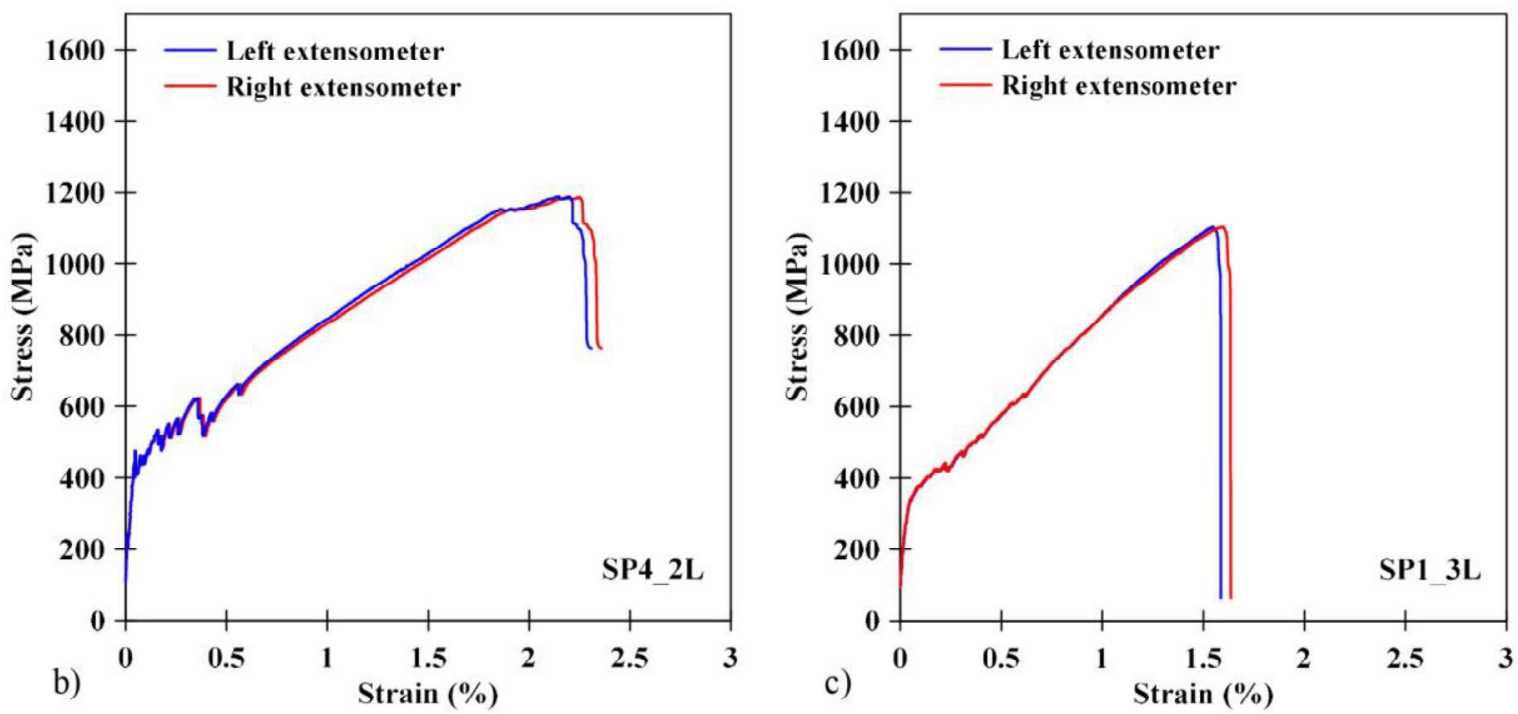

Fig. 12 Stress-strain curves obtained from virtual extensometers placed on the side of the specimens: a) position of virtual extensometers; b) specimen SP4_2L; c) specimen SP1_3L

\subsubsection{Load-strain curves}

In order to discuss the characteristic behaviour of the employed mortar-based system under tension, Fig. 13a shows the experimental results of the SP1_2L specimen, with annotations of typical stages, transition points and load drops. As already known in the literature [9], the curve shows a trilinear trend corresponding to three stages: un-cracked Stage I, crack development Stage II and cracked Stage III. The evolution of the crack pattern is also shown in Fig. 13b, where each image corresponds to a specific point of the load-strain curve in Fig. 13a. 


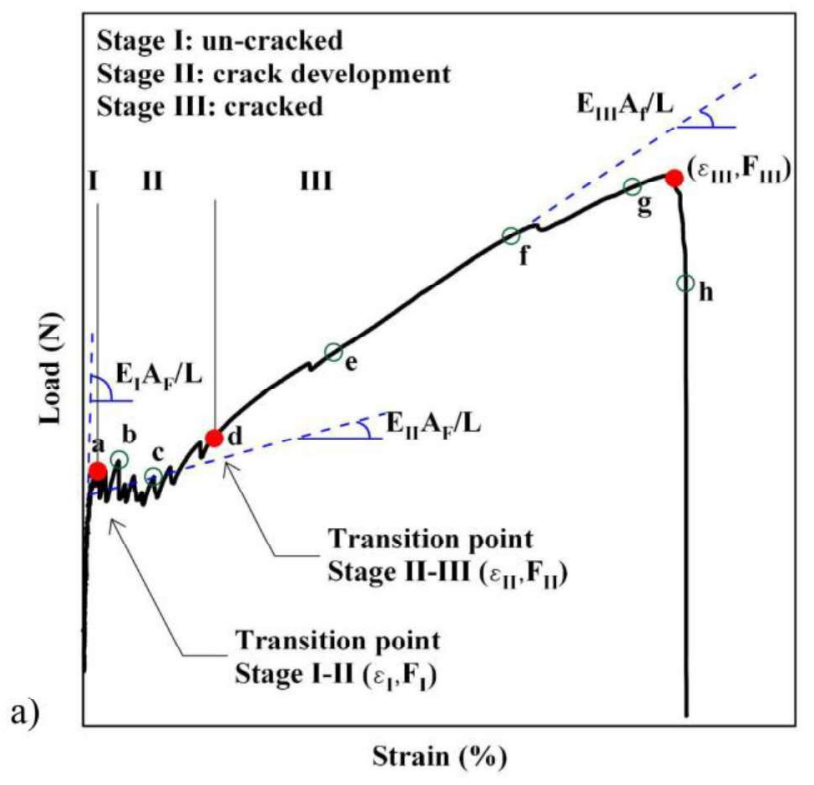

b)

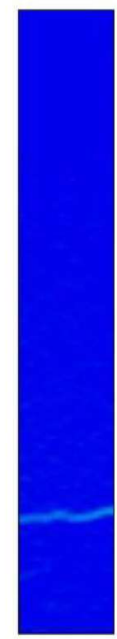

a

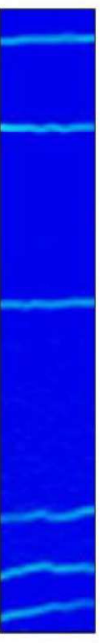

b

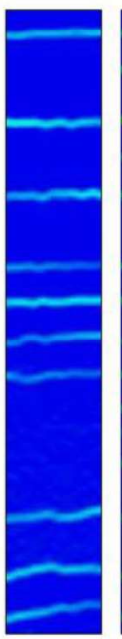

c

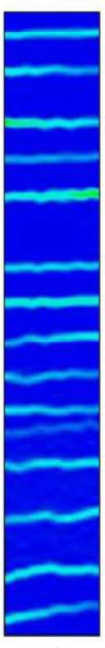

d

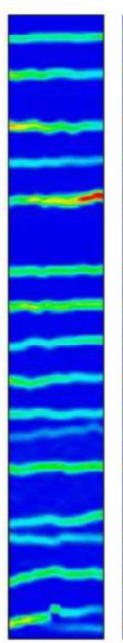

e

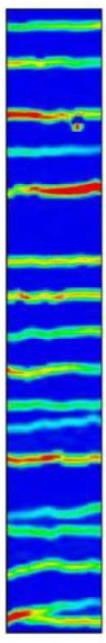

f

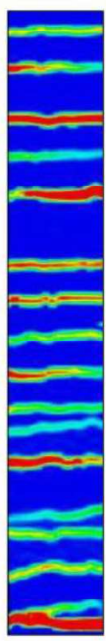

g

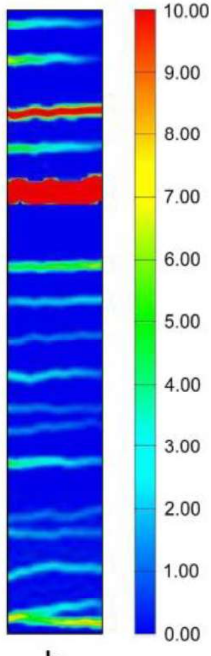

h

Fig. 13 Tensile response of composite specimen SP1_2L: a) Load-strain curve annotated with typical stages and transition points; b) crack pattern evolution corresponding to annotations (points a-h)

The influence of the number of reinforcing grid layers on the load capacity of the BFRCM coupons can be observed on the load-strain curves plotted in Fig. 14. For each specimen the values of peak load, stress, strain and slope of the three-linear curves are reported in Table 3 together with average and COV values.

The initial slope of the curves is similar for all the tested specimens. The transition from Stage I to Stage II for onelayer reinforced specimens is characterized by significant load drops. Conversely, coupons with multiple grid layers make for a more gradual stress redistribution from the matrix to the reinforcement and a smoother transition from Stage I to Stage II. 


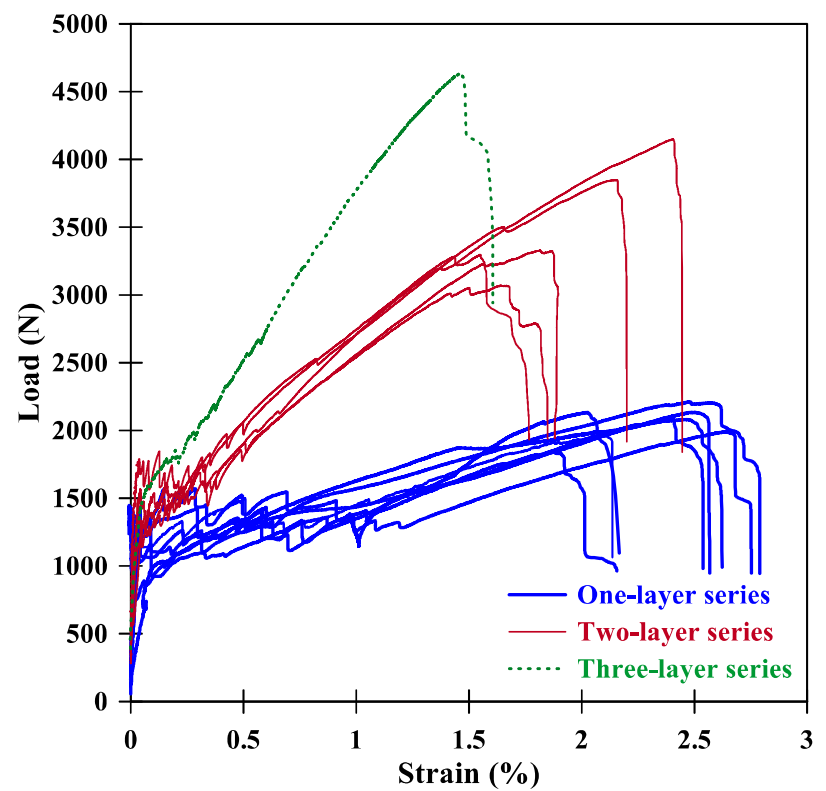

Fig. 14 Load-strain curves of BFRCM composite coupons

The slope of Stage II was evaluated by fitting the stress-strain curve between points $\left(\sigma_{\mathrm{I}}, \varepsilon_{\mathrm{I}}\right)$ and $\left(\sigma_{\mathrm{II}}, \varepsilon_{\mathrm{II}}\right)$, which in general produces a slope different from the one obtained by connecting points $\left(\sigma_{\mathrm{I}}, \varepsilon_{\mathrm{I}}\right)$ and $\left(\sigma_{\mathrm{II}}, \varepsilon_{\mathrm{II}}\right)$ [2]. It can be noted that in Stage II the slope increases with the number of grid layers, while the extension of the crack development stage is larger for specimens reinforced with one layer $\left(\varepsilon_{I I}=1.019\right)$ compared to two and three-layer samples $\left(\varepsilon_{I I}=0.448\right.$ and $\varepsilon_{I I}$ $=0.229$ respectively) (Table 3). Moreover, the volume fraction of fibres influences the number of cracks developed during Stage II, as evidenced by the number of load drops. This is also reflected in the crack pattern plotted in Fig. 15 where specimens with two and three reinforcement layers show a larger number of progressively closely spaced cracks compared to the one-layer series. 

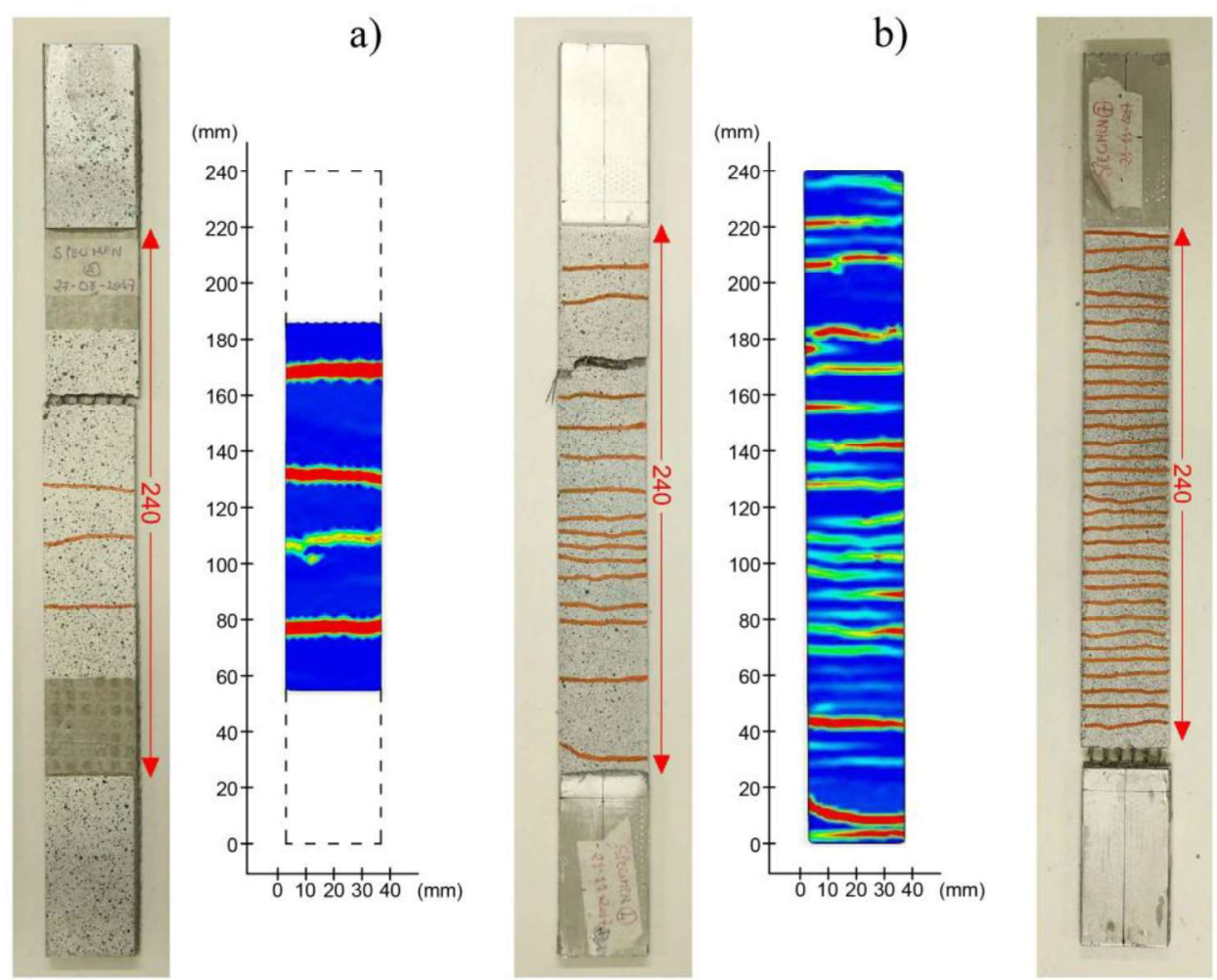

c)

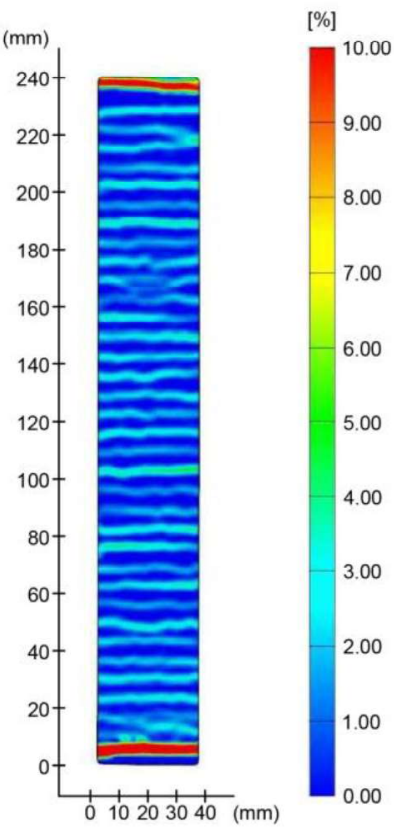

Fig. 15 Crack pattern at failure load: a) one-layer reinforced specimen (SP8_1L); b) two-layer reinforced specimen (SP2_2L); c) three-layer reinforced specimen (SP1_3L)

Regarding the load capacity, BFRCM coupons with higher reinforcement ratio carry higher loads, however the load increments are not proportional to the reinforcement area: for Stage I load increments equal to $+17 \%$ and $+16 \%$ were recorded for coupons reinforced with two and three layers respectively compared to the SP_1L series; for Stage II the increments were equal to $+33 \%$ and $30 \%$. The average maximum forces $\mathrm{F}_{\mathrm{I}}$ and $\mathrm{F}_{\mathrm{II}}$ recorded at the end of Stage I and II for the three series of specimens are not subjected to large variations as they are mostly influenced by the mechanical properties of the mortar ( $\mathrm{F}_{\mathrm{I}}$ equal to $1.23 \mathrm{kN}, 1.45 \mathrm{kN}$ and $1.44 \mathrm{kN} ; \mathrm{F}_{\text {II }}$ equal to $1.40 \mathrm{kN}, 1.85 \mathrm{kN}$ and $1.82 \mathrm{kN}$ ).

Therefore, during the crack development stages adding a second reinforcement layer increases slightly the capacity, however, the third layer has a negligible effect. On the other hand, Stage III peak load values depend mostly on the reinforcement area and the bearing capacity increases significantly with the number of grid layers $\left(\mathrm{F}_{\mathrm{III}}\right.$ equal to $2.05 \mathrm{kN}$, $3.54 \mathrm{kN}$ and $4.63 \mathrm{kN}$ for one-, two- and three-layer specimens). These values correspond to load increments equal to $+72 \%$ and $+125 \%$ compared to the one-layer samples. 
Table 3: Results of BFRCM coupons in Stage I, II and III

\begin{tabular}{|c|c|c|c|c|c|}
\hline & Samples & Peak load [N] & Peak stress [MPa] & Strain [\%] & Tangent modulus [GPa] \\
\hline \multirow{17}{*}{ 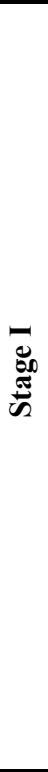 } & & $F_{I}$ & $\sigma_{I}=F_{I} / A_{f}$ & $\varepsilon_{I}$ & $E_{I}$ \\
\hline & SP1_1L ${ }^{*}$ & - & - & - & - \\
\hline & SP2_1L & 1306.85 & 933.46 & 0.048 & 1947.14 \\
\hline & SP3_1L & 756.24 & 540.17 & 0.015 & 3684.67 \\
\hline & SP4_1L & 1067.87 & 762.76 & 0.034 & 2233.56 \\
\hline & SP5_1L & 1427.38 & 1019.56 & 0.042 & 2432.16 \\
\hline & SP6_1L & 1446.39 & 1033.13 & 0.018 & 5739.64 \\
\hline & SP7_1L & 1315.78 & 939.84 & 0.021 & 4475.45 \\
\hline & SP8_1L & 1318.24 & 941.60 & 0.035 & 2653.89 \\
\hline & $\begin{array}{l}\text { Average } \\
(\mathrm{COV} \%) \\
\end{array}$ & $\begin{array}{l}1234.11 \\
(19.8 \%) \\
\end{array}$ & $\begin{array}{l}881.50 \\
(19.8 \%) \\
\end{array}$ & $\begin{array}{l}0.030 \\
(41.8 \%) \\
\end{array}$ & $\begin{array}{l}3309.50 \\
(42 \%)\end{array}$ \\
\hline & SP1_2L & 1788.57 & 638.77 & 0.038 & 1690.90 \\
\hline & SP2_2L & 1491.68 & 532.74 & 0.031 & 1722.97 \\
\hline & SP3_2L & 1063.47 & 379.81 & 0.015 & 2566.29 \\
\hline & SP4_2L & 1331.08 & 475.39 & 0.048 & 987.92 \\
\hline & SP5_2L & 1566.32 & 559.40 & 0.041 & 1353.67 \\
\hline & $\begin{array}{l}\text { Average } \\
(\mathrm{COV} \%)\end{array}$ & $\begin{array}{l}1448.22 \\
(18.7 \%)\end{array}$ & $\begin{array}{l}517.22 \\
(18.7 \%)\end{array}$ & $\begin{array}{l}0.035 \\
(36.7 \%)\end{array}$ & $\begin{array}{l}1664.35 \\
(35.2 \%)\end{array}$ \\
\hline & SP1_3L & 1437.38 & 342.23 & 0.044 & 786.74 \\
\hline \multirow{17}{*}{ 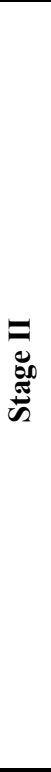 } & & $F_{I I}$ & $\sigma_{I I}=F_{I I} / A_{f}$ & $\varepsilon_{I I}$ & $E_{I I}$ \\
\hline & SP1_1L ${ }^{*}$ & - & - & - & - \\
\hline & SP2_1L & 1318.42 & 941.73 & 0.826 & 9.33 \\
\hline & SP3_1L & 1264.24 & 903.03 & 0.862 & 38.57 \\
\hline & SP4_1L & 1426.55 & 1018.96 & 1.145 & 26.33 \\
\hline & SP5_1L & 1517.34 & 1083.82 & 1.202 & 6.05 \\
\hline & SP6_1L & 1430.40 & 1021.71 & 0.979 & 18.55 \\
\hline & SP7_1L & 1523.73 & 1088.38 & 0.874 & 11.53 \\
\hline & SP8_1L & 1305.57 & 932.55 & 1.242 & 8.70 \\
\hline & $\begin{array}{l}\begin{array}{l}\text { Average } \\
(\mathrm{COV} \%)\end{array} \\
\end{array}$ & $\begin{array}{l}1398.03 \\
(7.4 \%) \\
\end{array}$ & $\begin{array}{l}998.60 \\
(7.4 \%) \\
\end{array}$ & $\begin{array}{l}1.019 \\
(17.2 \%) \\
\end{array}$ & $\begin{array}{l}17.01 \\
(69.2 \%) \\
\end{array}$ \\
\hline & SP1_2L & 1973.63 & 704.87 & 0.458 & 18.66 \\
\hline & SP2_2L & 1693.58 & 604.85 & 0.383 & 31.07 \\
\hline & SP3_2L & 1896.52 & 677.33 & 0.411 & 65.45 \\
\hline & SP4_2L & 1885.00 & 673.21 & 0.531 & 40.87 \\
\hline & SP5_2L & 1827.60 & 652.71 & 0.460 & 26.48 \\
\hline & $\begin{array}{l}\text { Average } \\
(\mathrm{COV} \%) \\
\end{array}$ & $\begin{array}{l}1855.26 \\
(5.6 \%) \\
\end{array}$ & \begin{tabular}{l|l|}
662.59 \\
$(5.6 \%)$ \\
\end{tabular} & $\begin{array}{l}0.448 \\
(12.5 \%)\end{array}$ & \begin{tabular}{l|l}
36.51 \\
$(49.5 \%)$ \\
\end{tabular} \\
\hline & SP1_3L & 1821.68 & 433.73 & 0.229 & 43.78 \\
\hline \multirow{17}{*}{ 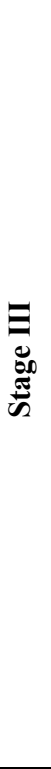 } & & $F_{I I I}$ & $\sigma_{I I I}=F_{I I I} / A_{f}$ & $\varepsilon_{I I I}$ & $E_{I I I}$ \\
\hline & SP1_1L & 2080.92 & 1482.14 & 2.463 & - \\
\hline & SP2_1L & 1964.19 & 1402.99 & 2.096 & 36.31 \\
\hline & SP3_1L & 2132.64 & 1523.32 & 2.028 & 53.22 \\
\hline & SP4_1L & 1841.98 & 1315.70 & 1.876 & 40.61 \\
\hline & SP5_1L & 2134.09 & 1524.35 & 2.503 & 33.86 \\
\hline & SP6_1L & 2083.79 & 1488.42 & 2.392 & 33.01 \\
\hline & SP7_1L & 2211.45 & 1579.61 & 2.577 & 28.84 \\
\hline & SP8_1L & 1990.37 & 1421.69 & 2.643 & 34.93 \\
\hline & $\begin{array}{l}\text { Average } \\
\text { (COV \%) }\end{array}$ & $\begin{array}{l}2054.93 \\
(5.7 \%)\end{array}$ & $\begin{array}{l}1467.28 \\
(5.7 \%)\end{array}$ & $\begin{array}{l}2.322 \\
(12.2 \%)\end{array}$ & $\begin{array}{l}37.25 \\
(21.2 \%)\end{array}$ \\
\hline & SP1_2L & 3847.49 & 1374.10 & 2.151 & 39.53 \\
\hline & SP2_2L & 4149.43 & 1481.94 & 2.405 & 43.38 \\
\hline & SP3_2L & 3295.68 & 1177.03 & 1.549 & 43.89 \\
\hline & SP4_2L & 3328.44 & 1188.73 & 1.815 & 40.14 \\
\hline & SP5_2L & 3069.95 & 1096.41 & 1.641 & 37.56 \\
\hline & $\begin{array}{l}\text { Average } \\
\text { (COV \%) }\end{array}$ & \begin{tabular}{l|}
3538.20 \\
$(12.6 \%)$
\end{tabular} & $\begin{array}{l}1263.64 \\
(12.6 \%) \\
\end{array}$ & $\begin{array}{l}1.912 \\
(18.8 \%)\end{array}$ & \begin{tabular}{l|}
40.90 \\
$(6.6 \%)$ \\
\end{tabular} \\
\hline & SP1_3L & 4633.19 & 1103.14 & 1.466 & 54.13 \\
\hline
\end{tabular}

* Results neglected for the evaluation of the average values 


\subsubsection{Stress-strain curves}

Fig. 16 presents the stress-strain curves of the three sets of BFRCM coupons together with a trilinear curve defined by the average transition points reported in Table 3 . It should be noted that in the case of series reinforced with two and three layers, the curve passing by transition points can be considered almost bilinear because of the similar slope of Stage II and Stage III. In Fig. 16d the trilinear/bilinear curves of one-, two- and three-layer reinforced specimens are compared to the average stress-strain curve of the basalt grid (warp direction).
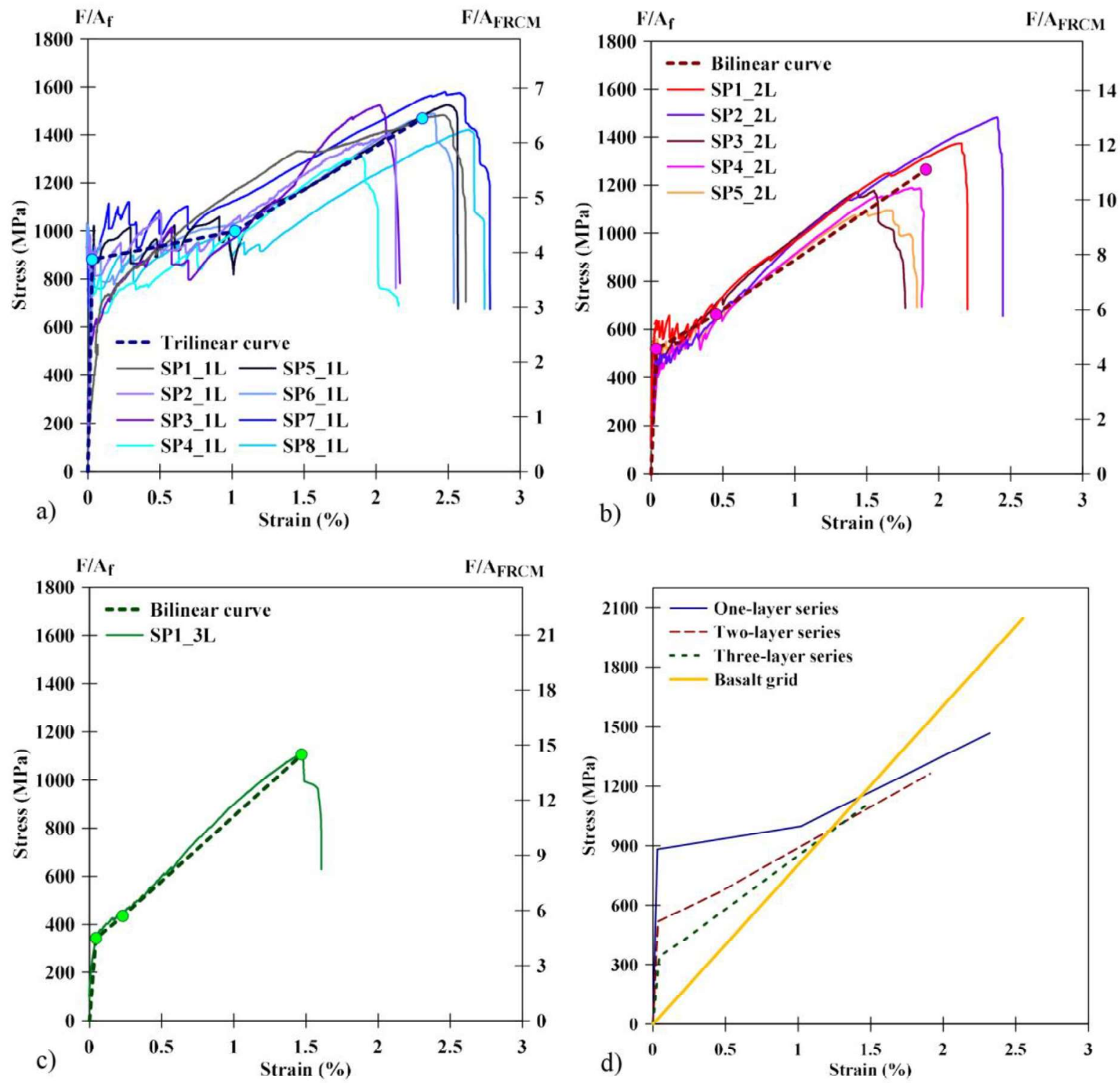

Fig. 16 Stress-strain curves of BFRCM composite coupons: a) one-layer reinforced samples; b) two-layer reinforced samples; c) three-layer reinforced sample; d) trilinear/bilinear curves of BFRCM series and basalt grid

The tensile stresses $\sigma$ on the left y axis, are calculated using the cross sectional area of the grid only $\left(\mathrm{F} / \mathrm{A}_{\mathrm{f}}\right)$, as suggested by the code AC434 (2016) [4] and studies in the literature [9] [22]. Additionally, the secondary y axis in Fig. 
16 shows the tensile stresses evaluated using the geometrical area of the FRCM system, AFRCM, according to the recent RILEM recommendations about test methods for FRCM materials [5].

The stress-strain curves in Fig. 16 show that the maximum stress at the end of each stage decreases as the number of reinforcement layers increases. This occurs for the first and second branch and in a less marked way for the third branch (stress at failure). Two-layer series compared to one-layer series showed an average decrease of $41 \%, 34 \%, 14 \%$ respectively for Stage I, II and III, while the same decreases for specimens reinforced with three layers were equal to $61 \%, 57 \%$ and $25 \%$ respectively. The stress reductions are more marked in the case of higher reinforcement ratio and this may be due to the reduced thickness of mortar between grid layers in over-reinforced specimens. The small thickness of mortar did not allow an adequate adhesion to the textile and redistribution of the stresses between the cords of the grid. The average stress in the mortar $\left(\sigma_{\mathrm{I}, \mathrm{m}}\right)$ at the end of Stage I (cracking load), evaluated using the equivalent composite area, was 3.60 MPa, 4.15 MPa and 3.87 MPa for one-, two- and three-layer specimens. These values were respectively $49 \%, 42 \%$ and $46 \%$ lower than the tensile strength of the mortar $(7.18 \mathrm{MPa})$. This is not unexpected as three point bending tests may produce an overestimation of the tensile strength of the mortar.

The response curves of some two-layer reinforced specimens (SP3_2L, SP4_2L, SP5_2L) show a loss of linearity in Stage III and/or load drops before the reaching of the maximum stress (Fig. 16b), caused by slight slipping or failure of one of the chords leading to a non-uniform load distribution over the cross-section of the grid.

In regard to strain values, the averages of the three series were quite close for Stage I $(0.030 \%, 0.035 \%, 0.044 \%)$. For Stage II there was a marked reduction of the average maximum strain between one-layer specimens and two- and three-layer reinforced specimens, with a drop of $56 \%$ and $78 \%$ respectively. Finally, average strain reduction in Stage III was equal to $18 \%$ and $37 \%$ for two- and three-layer specimens respectively compared to one-layer specimens.

The extension of the crack development stage can be represented by the ratio $\varepsilon_{\text {III }} / \varepsilon_{\text {III }}$ (where $\varepsilon_{\text {III }}$ is the strain at peak stress). In specimens reinforced with one basalt layer, $\varepsilon_{\text {II }}$ was on average $45 \%$ of the ultimate strain (values ranging between $34 \%$ and $61 \%$ ), pointing out that the crack development stage was quite extended. On the other hand, $\varepsilon_{\text {II }}$ was on average equal to $24 \%$ (values ranging between $16 \%$ and $29 \%$ ) and $16 \%$ of the ultimate strain for two- and threelayer reinforced specimens respectively, as transversal yarns weaken the cross section and induce cracking. This leads to a quicker cracking process for smaller values of deformation in samples with multiple grid layers [11].

The tangent modulus in Stage III increased with the number of grid layers, but all the series presented a considerable reduction of stiffness if compared with the average value obtained from basalt grid strips $(55 \%, 50 \%, 34 \%$ for one-, two- and three-layers respectively). 
Also, the values of tensile strength in Stage III $\left(\sigma_{\text {III }}\right)$ were quite low compared to the tensile strength of the basalt grid (Fig. 16d). To compare the strength of the BFRCM specimens with that of the basalt grid, the efficiency factor $\eta$, defined as the ratio between the tensile strength in composite coupons, $\sigma_{\text {III, }}$ and the average experimental strength of the grid, $\mathrm{f}_{\mathrm{fu}}$ is reported on Table 4 . The efficiency factor $\eta$ varied from 0.64 to 0.77 for one-layer reinforced specimens, from 0.54 to 0.72 for two-layer reinforced specimens, and was equal to 0.54 for the three-layer strengthened sample. These results underline the BFRCM coupons did not fully exploit the nominal capacity of the fibres, as also confirmed by [10] [11] [22]. The strength and stiffness reduction of composite specimens compared to the grid may be due to geometric defects of the grid, such as imperfect alignment of yarns, and possible damage of the fibres near to cracks edges. Misalignment, in particular, would influence more the BFRCM coupon than the grid strips for two reasons: 1) the composite coupons width was larger than the grid strips (size effect) and 2) BFRCM coupons were obtained by cutting from a 500x500mm slab, see Fig. 3, as recommended by the AC434 American Standard [4]. Therefore, geometric misalignment would accumulate and would not be easy to detect due to the mortar layers covering the grid.

Table 4: Evaluation of efficiency factor $\eta$

\begin{tabular}{|c|c|c|c|}
\hline \multirow[t]{2}{*}{ Samples } & $\begin{array}{c}\text { Peak stress } \\
{[\mathrm{MPa}]} \\
\end{array}$ & Efficiency factor & \multirow[t]{2}{*}{ Range of variation } \\
\hline & $\sigma_{\text {III }}$ & $\eta$ & \\
\hline SP1_1L & 1482.14 & 0.72 & \multirow{8}{*}{$0.64-0.77$} \\
\hline SP2_1L & 1402.99 & 0.69 & \\
\hline SP3_1L & 1523.32 & 0.74 & \\
\hline SP4_1L & 1315.70 & 0.64 & \\
\hline SP5_1L & 1524.35 & 0.75 & \\
\hline SP6_1L & 1488.42 & 0.73 & \\
\hline SP7_1L & 1579.61 & 0.77 & \\
\hline SP8_1L & 1421.69 & 0.70 & \\
\hline SP1_2L & 1374.10 & 0.67 & \multirow{5}{*}{$0.54-0.72$} \\
\hline SP2_2L & 1481.94 & 0.72 & \\
\hline SP3_2L & 1177.03 & 0.58 & \\
\hline SP4_2L & 1188.73 & 0.58 & \\
\hline SP5_2L & 1096.41 & 0.54 & \\
\hline SP1_3L & 1103.14 & 0.54 & - \\
\hline
\end{tabular}

\subsubsection{Crack opening and displacement fields}

In this section the displacement field analysis carried out using the DIC of the front surface of three composite specimens is reported. The analysis was aimed at gaining information on the location of the cracks and their opening and evolution during the tests. The analysis was carried out for specific load steps as shown in Fig. 17 (red points), on specimens SP8_1L, SP4_2L and SP1_3L reinforced with one, two and three basalt grid layers respectively. The curves 
in Fig. 18 show the displacement obtained with the DIC along the longitudinal direction of the samples, for the same load steps. The $\mathrm{x}$ axis shows the longitudinal axis of the BFRCM strips. Each displacement step is representative of a crack opening and the difference between values of displacement at the extremes of each step measures the crack opening. The distance between displacement steps corresponds to the distance between subsequent cracks. The outcomes show that the distance between cracks is in the range $25-40 \mathrm{~mm}$ (mean value $33 \mathrm{~mm}$ ) and 6-34 mm (mean value $14 \mathrm{~mm}$ ) for one and two-layer reinforced specimens respectively. For three-layer sample, the crack distance ranges between 5 and $10 \mathrm{~mm}$, with an average value of $7 \mathrm{~mm}$, which is close to the spacing of the transversal yarns of the basalt mesh $(6 \mathrm{~mm})$. Indeed, transversal yarns caused local reduction of the mortar section which became a preferential weak location for the development of cracks, as already observed in the literature [22]. This was even truer for the specimen SP1_3L because of the presence of more basalt grid layers separated by a lower thickness of mortar.

From the graphs is clear that the volume fraction of fibres influences not only the number of cracks and the distance between cracks, but also the crack opening, which decreases with the increase of the number of reinforcing layers, as discussed in the following. 

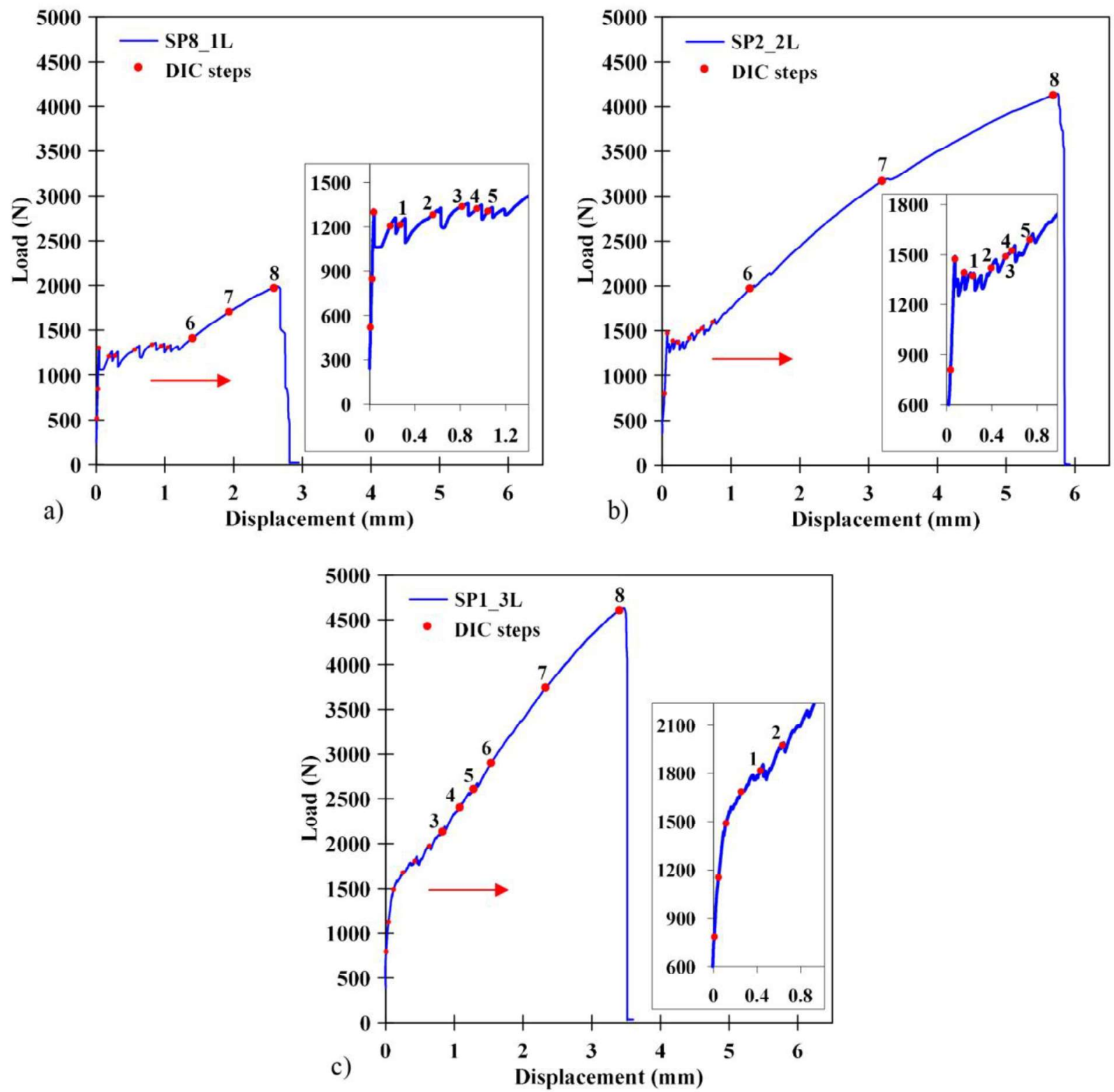

Fig. 17 Load-displacement curves: a) one-layer reinforced specimen (SP8_1L); b) two-layer reinforced specimen (SP2_2L); c) three-layer reinforced specimen (SP1_3L) 

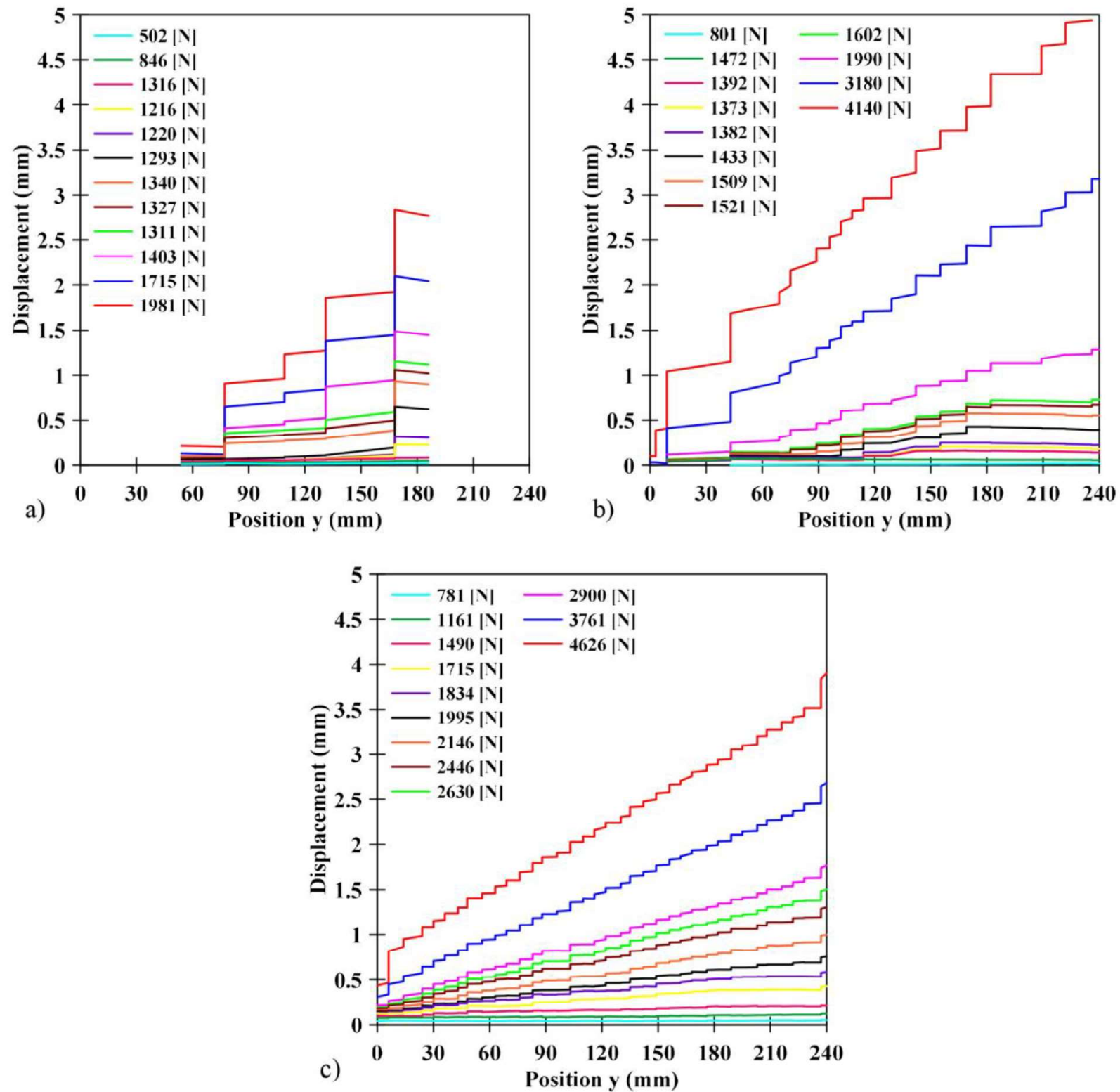

Fig. 18 Displacement along the strip longitudinal axis for different loading steps: a) one-layer reinforced specimen SP8_1L; b) two-layer reinforced specimen SP2_2L; c) three-layer reinforced specimen SP1_3L

Fig. 19, Fig. 20 and Fig. 21 present the continuous displacement contours related to the three specimens (SP8_1L, SP2_2L, SP1_3L) for the load steps from 1 to 8 identified in Fig. 17. In the images, the reported iso-lines represent points with equal displacement. The evolution of the crack pattern is clearly detectable and is characterized by the progressive development of cracks transversal to the direction of the applied load. It is worth noting that for the onelayer specimen the isolines are not horizontal, pointing to a non-uniform stress distribution on the strip sections. The first crack develops at the top of the strip $(y=168 \mathrm{~mm})$ and keeps opening until a second one opens at the bottom ( $\mathrm{y}=77$ $\mathrm{mm}$ ) followed by two more in the central zone $(\mathrm{y}=131 \mathrm{~mm}$ and $\mathrm{y}=109 \mathrm{~mm})$. In the two- and three-layer specimens the isolines are mostly horizontal with some vertical lines forming in Stage III possibly due to a slight slipping or yarn damaging at the top side of the strip. Isolines are also closer and develop in a larger number of cracks. 
Fig. 22 shows the evolution of the crack opening as a function of the external load. In the graphs, each curve corresponds to one crack and the label of the curve refers to the position of the crack on the coupon. The graphs point out that the maximum crack opening in one-layer reinforced specimen (SP8_1L) was much larger compared to that measured in samples reinforced with two layers. The same decrease of crack opening was observed when the specimen was strengthened with three basalt layers, compared to the sample reinforced with two grid layers. Moreover, this opening increase was inversely proportional to the number of cracks developed along the surface of the composite coupons: the greater the number of cracks, the lower the maximum crack opening recorded.

For values of load corresponding to the uncracked stage (Stage I) and crack development stage (Stage II), the trend of the load-crack opening curve is inhomogeneous, because of the different opening endured by different cracks. Conversely, once the Stage III starts, the curves begin to be almost parallel. 

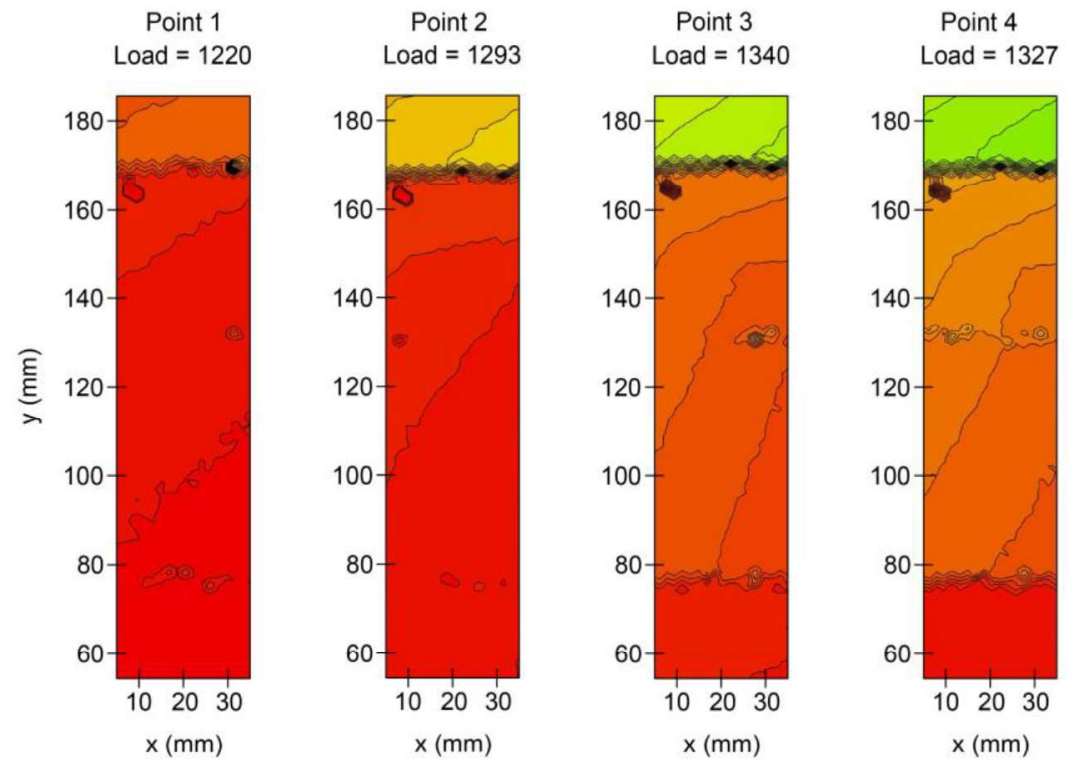

[mm]
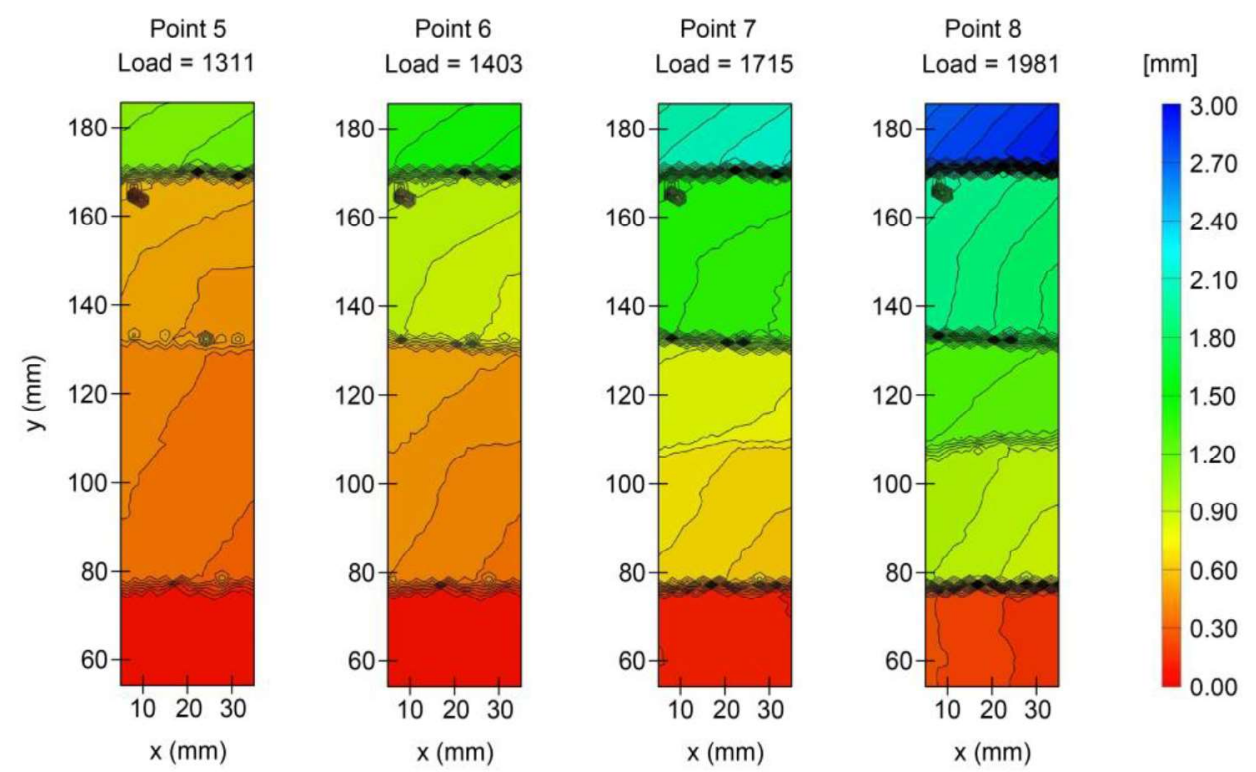

Fig. 19 Displacement field of specimen SP8_1L 

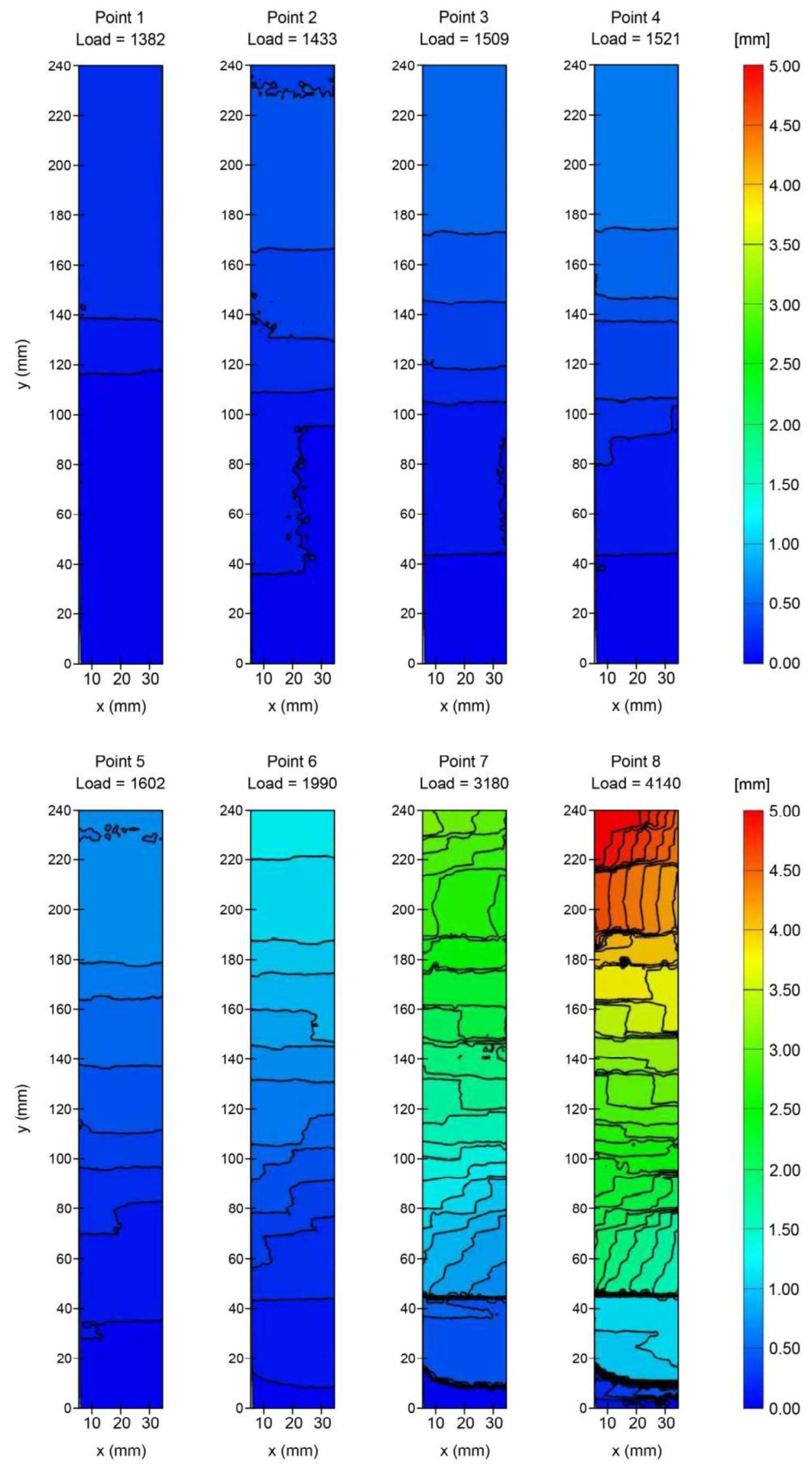

Fig. 20 Displacement field of specimen SP2_2L 

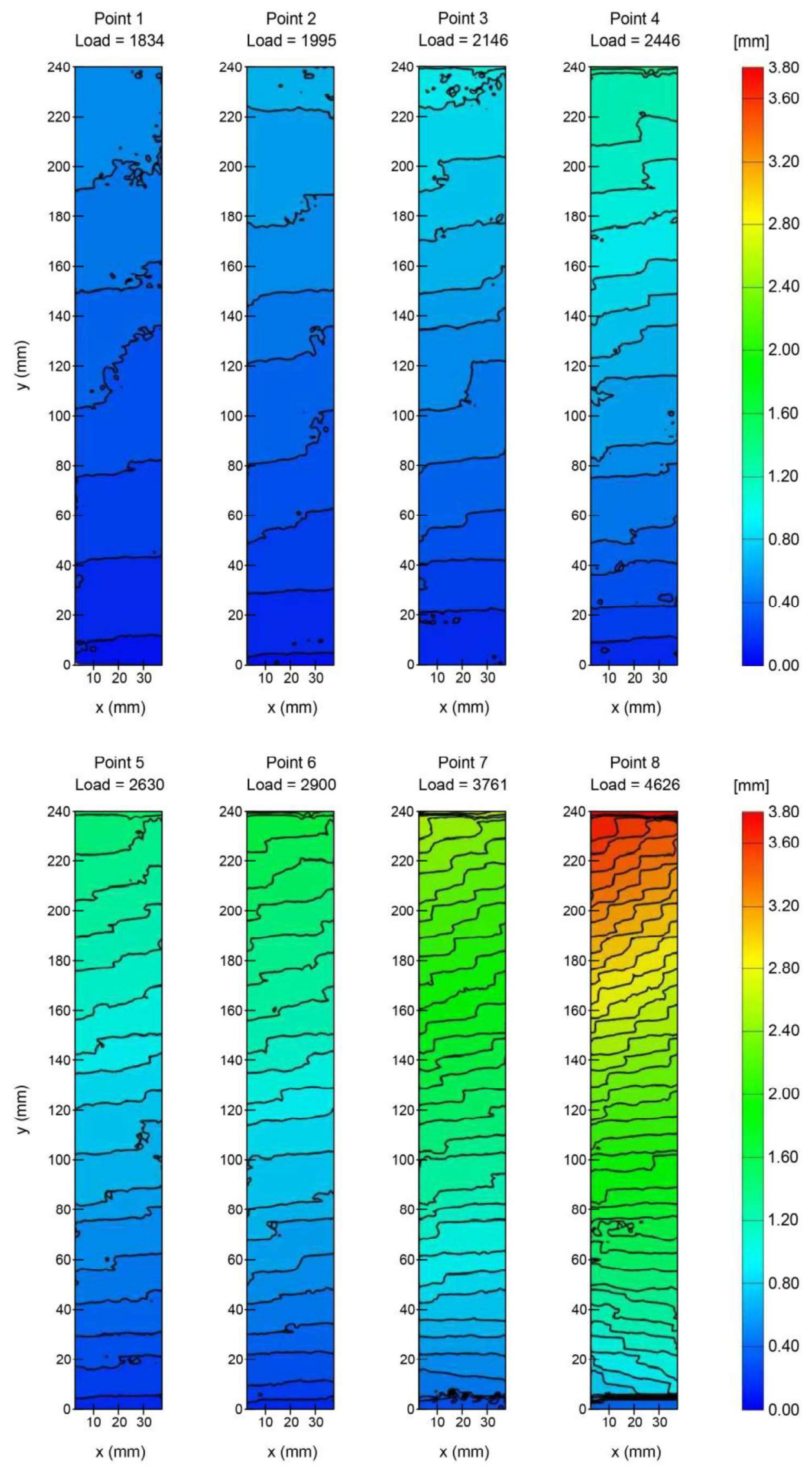

Fig. 21 Displacement field of specimen SP1_3L

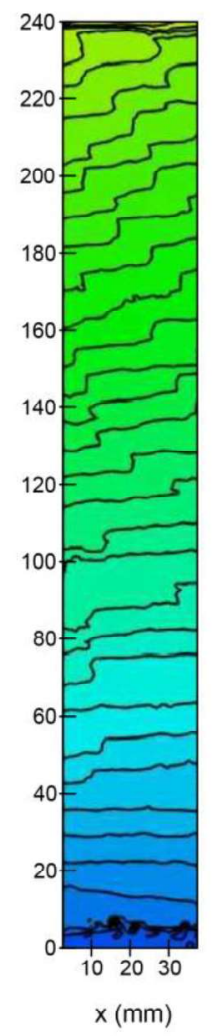


Moreover, the graphs in Fig. 22 depict the ratio $E_{f} A_{f} / L$, where $E_{f}$ and $A_{f}$ are the Young's modulus and the cross sectional area of the grid, and $L$ indicates the distance between cracks. The three elongation curves $E_{f} A_{f} / L$ vs external load reported in Fig. 22 were obtained considering a strip length L equal to 33, 14 and $7 \mathrm{~mm}$ respectively for specimens SP8_1L, SP2_2L and SP1_3L, equal to the average distance between cracks. As it can be noted from the graph, the slope of the crack opening vs load curves in Stage III is close to the grid deformability $\left(\mathrm{E}_{\mathrm{f}} \mathrm{A}_{\mathrm{f}} / \mathrm{L}\right)$. This show that tension stiffening effect of the mortar within the crack spacing can be considered negligible for all the specimens.
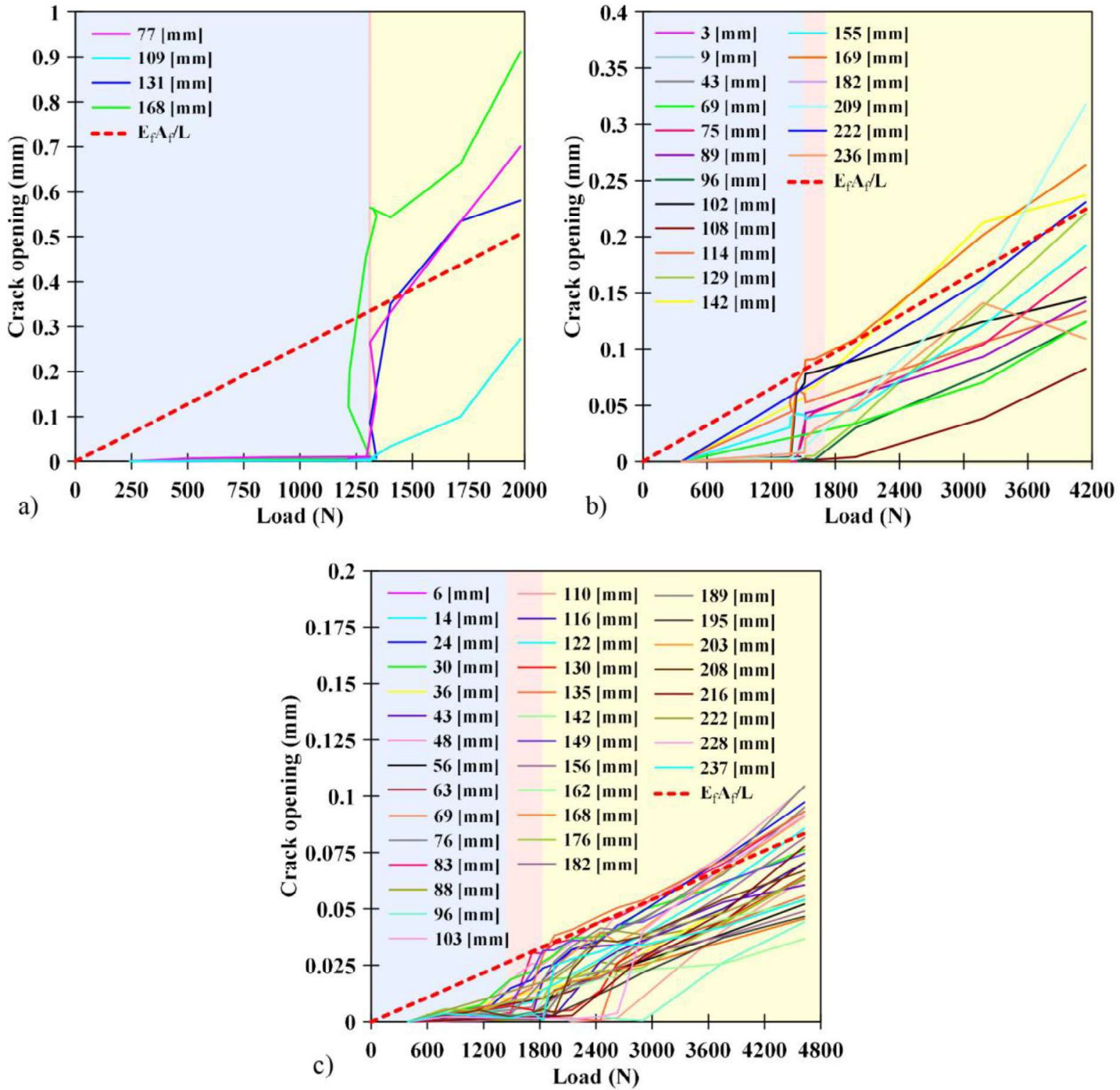

Fig. 22 Evolution of crack opening as a function of the applied load: a) specimen SP8 1L; b) specimen SP2 2L; c) specimen SP1_3L 


\subsubsection{Failure modes}

Fig. $23 \mathrm{a}$ and $\mathrm{b}$ show respectively the BFRCM specimens with one and two grid layers at failure. Fibre tensile failure was observed for all the tested specimens, including rupture near the gripping area or in the middle of the sample.

The development of cracks near the gripping area did not affect the load-displacement and stress-strain curves. Also, other authors [20] showed that the peak loads associated to this failure mode are comparable to those attained when the main crack develops in the middle of the specimen. Moreover, even when ruptures occurred near the clamping areas, reliable strain values were obtained using DIC, which allowed a full length measurement of strains.

Most failures were recorded in a cross section comprising a transversal yarn of the mesh (Fig. 24 a and b): the presence of rovings in the transversal direction caused a local reduction of the mortar cross-section with consequent reduction of its resistance, as already observed in the literature [22].

The analysis of the specimens after failure showed sliding between external and internal fibres of the yarns, namely a telescopic failure (Fig. 24 a) [20]. This is due to the fact that in coated textiles the load is transferred from the mortar matrix to the coating external layer by chemical adhesion and, later, from the external layer to the inner core by friction, because of the impossibility of the mortar to impregnate the inner fibres. Being the matrix-to-fibre transfer capacity higher than that between fibres, telescopic pull-out failure may occur [23]. The failure mechanism of the yarns started with the fracture of the outer filaments, followed by the rupture of adjacent fibres, until reaching the core filaments, which were not in direct contact with the mortar (Fig. 24 a).

For some specimens, failure occurred at all the yarns simultaneously; in other cases, the failure was characterized by progressive damage of one or few lateral yarns. This is confirmed by the dentate post-peak behaviour of some loadstrain curves evidencing the close progressive rupture of the basalt yarns, which started from a side of the sample and propagated to the other side. 


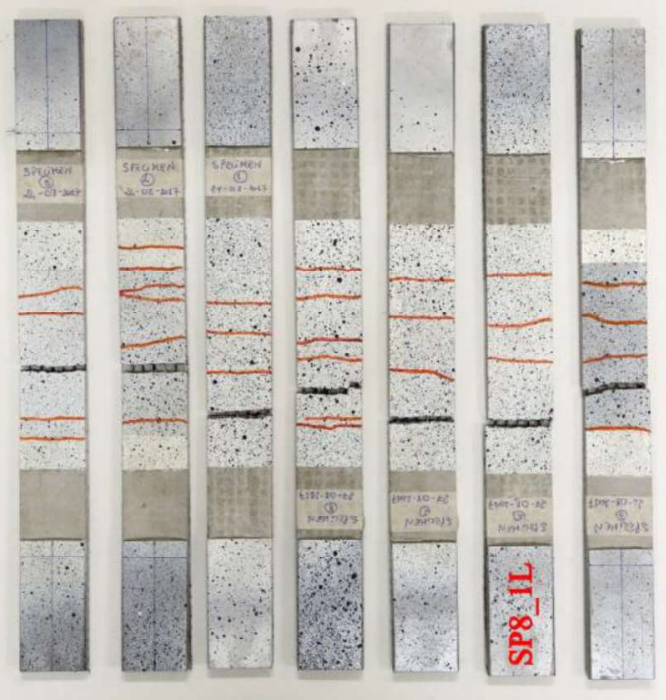

a)

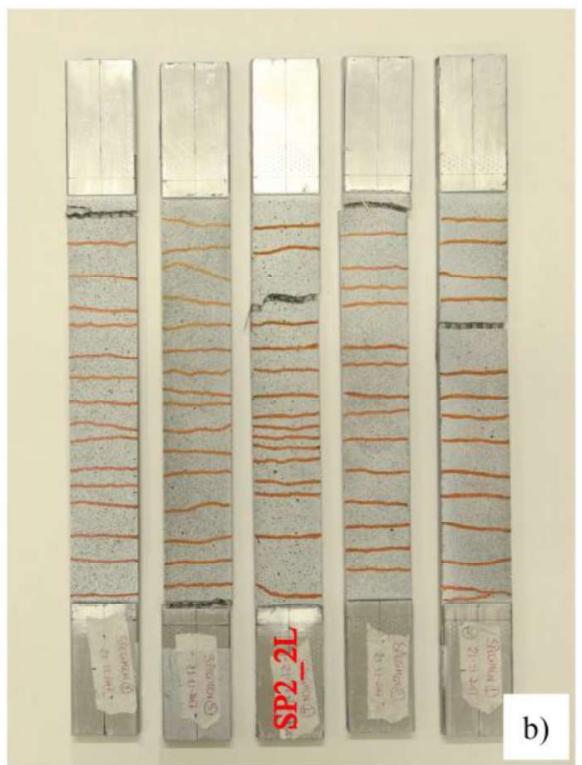

Fig. 23 BFRCM coupons after testing: a) one-layer reinforced specimens; b) two-layer reinforced specimens
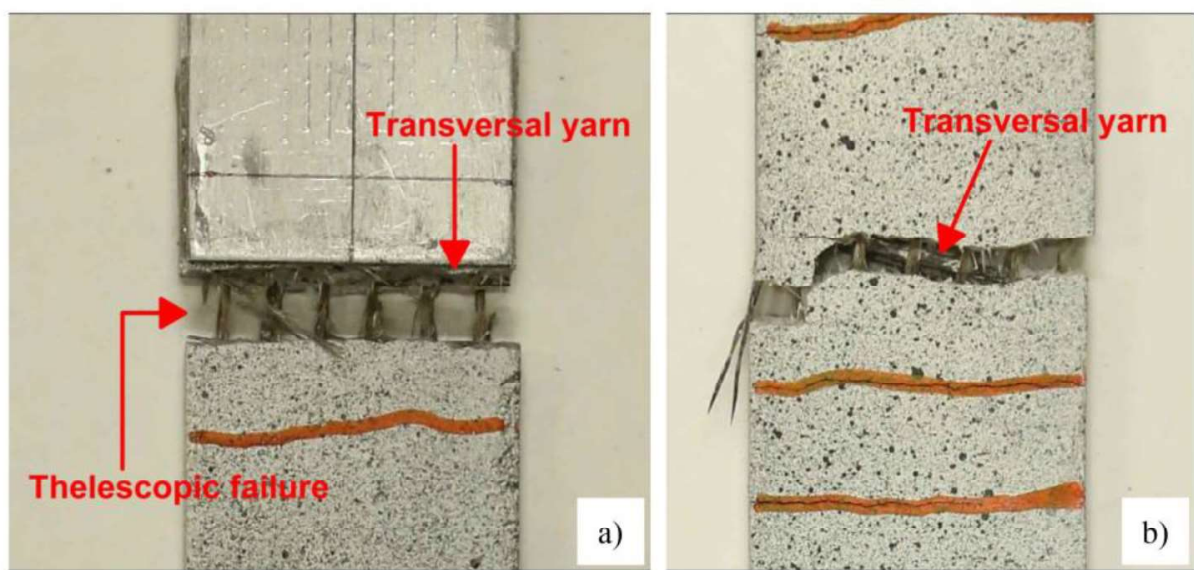

Fig. 24 Failure mode of BFRCM specimens: a) thelescopic failure of grid longitudinal yarns and crack at the transversal yarn b) critical crack at the transversal yarn

\section{Conclusions}

This paper presented an experimental study carried out on BFRCM coupons reinforced with one, two and three grid layers. Full field analysis of the coupon strain was carried out using DIC. From the experimental results and analyses the following conclusions can be made:

- The BFRCM samples were characterized by a trilinear behaviour, which was more marked in the case of onelayer reinforced strips showing a great extension of the crack development stage (Stage II); 
- The maximum tensile stress of BFRCM specimens decreased with the increase of the number of reinforcing basalt grid layers and the maximum average strength was reached by the series characterized by the lowest reinforcement ratio (SP_1L);

- The average peak stresses of the three series of specimens were lower compared to the peak stress of the dry basalt grid, with a decrease equal to $28 \%, 38 \%$ and $46 \%$ respectively for one, two and three-layer reinforced specimens. Similarly, the stiffness of the BFRCM series (SP_1L, SP_2L, SP_3L) in Stage III of the tensile curves proved to be lower than the Young's modulus of the dry basalt grid;

- The crack pattern was influenced by the reinforcement ratio. The higher the number of grid layers, the higher the number of cracks, which were closer together. Moreover, the crack opening during the tests was found to be influenced by the reinforcement ratio, with tighter cracks in the case of over-reinforced specimens.

- The tensile failure was observed for all the coupons, with rupture near the gripping area or in the middle of the samples. Most failures were recorded in a cross section including a transversal yarn of the basalt grid. Telescopic failure was observed between external and internal fibres of the yarns.

- Additional tests are recommended to support the results presented in this work, with reference to three-layer reinforced FRCM coupons.

\section{Acknowledgement}

This research was supported by a grant from the Italian Ministry for University and Research (MIUR) for PRIN2017 project "Innovative systems based on inorganic mortar and non metallic reinforcement for the upgrade of masonry structures and non structural elements". The financial support is gratefully acknowledged.

Activities for the research were developed among the Project ReLUIS "Progetto Esecutivo Accordo DPC/ReLUIS 2019-2021, WP14 - Contributi normativi per Materiali Innovativi per Interventi su Costruzioni Esistenti".

The authors thankfully acknowledge Bonifacio \& Cilia Edil Ceramica for providing the materials for the composite. 


\section{References}

[1] Bilotta A, Ceroni F, Nigro E, Pecce M. Experimental tests on FRCM strengthening systems for tuff masonry elements. Constr Build Mater 2017; 138: 114-133.

[2] D'Antino T, Papanicolaou C. Mechanical characterization of grid reinforced inorganic-matrix composites. Compos Part B-Eng 2017; 127: 78-91.

[3] Donnini J, Corinaldesi V. Mechanical characterization of different FRCM systems for structural reinforcement. Constr Build Mater 2017; 145: 565-575.

[4] ICC. AC434. Proposed Acceptance Criteria for Masonry and Concrete Strengthening Using Fibrereinforced Cementitious Matrix (FRCM) and Steel Reinforced Grout (SRG) Composite Systems. Whittier, CA: ICC-Evaluation Service, 2016.

[5] RILEM Technical Committee 232-TDT (Wolfgang Brameshuber) Mater Struct 2016, 49: 4923. doi:10. $1617 / \mathrm{s} 115270160839 \mathrm{z}$.

[6] Linea Guida per la identificazione, la qualificazione ed il controllo di accettazione di compositi fibrorinforzati a matrice inorganica (FRCM) da utilizzarsi per il consolidamento strutturale di costruzioni esistenti. Published by the Italian Ministry of Public Works, 2019.

[7] Dalalbashi A, Ghiassi B, Oliveira DV, Freitas A. Fibre-to-mortar bond behaviour in TRM composites: effect of embedded length and fibre configuration. Compos Part B-Eng 2018; 152: 43-57.

[8] Bellini A, Bovo M, Mazzotti C. Experimental and numerical evaluation of fibre-matrix interface behaviour of different FRCM systems. Compos Part B-Eng 2019; 161: 411-426.

[9] Ascione L, de Felice G, De Santis S. A qualification method for externally bonded Fibre Reinforced Cementitious Matrix (FRCM) strengthening systems. Compos Part B-Eng 2015; 78, 497-506.

[10] Bilotta A, Ceroni F, Lignola GP., Prota A. Use of DIC technique for investigating the behaviour of FRCM materials for strengthening masonry elements. Compos Part B-Eng 2017; 129. 251-270.

[11] Caggegi C, Lanoye E, Djama K, Bassil A, Gabor A. Tensile behaviour of a basalt TRM strengthening system: influence of mortar and reinforcing grid ratios. Compos Part B-Eng 2017; 130: 90-102.

[12] Tekieli M, De Santis S, de Felice G, Kwiecień A, Roscini F. Application of Digital Image Correlation to composite reinforcements testing. Compos Struct 2017; 160: 670-688.

[13] D'Antino T, Papanicolaou C. Comparison between different tensile test set-ups for the mechanical characterization of inorganic-matrix composites. Constr Build Mater 2018; 171: 140-151.

[14] Donnini J, Chiappini G, Lancioni G, Corinaldesi V. Tensile behaviour of glass FRCM systems with fabrics' overlap: experimental results and numerical modeling. Compos Struct 2019; 212: 398-411.

[15] Bramato G, Cascardi A, Micelli F, Aiello MA. Tensile Characterization of Multi-Ply Fabric-Reinforced Cementitious Matrix. Proc. In: 3rd RILEM spring convention 2020 - Ambitioning A Sustainable Future For Built Environment: Comprehensive Strategies For Unprecedented Challenges, March 10-14 (2020). Guimarães, Portugal.

[16] Younis A, Ebead U, Shrestha K. Tensile characterization of multi- ply fabric- reinforced cementitious matrix strengthening systems. Struct Concrete 2020; 21(2): 713-723.

[17] Donnini J, Corinaldesi V. Mechanical characterization of different FRCM systems for structural reinforcement. Constr Build Mater 2017; 145: 565-575. 
[18] ISO 13934-1. Textiles - Tensile properties of fabrics - Part 1: Determination of maximum force and elongation at maximum force using the strip method. CEN - European Committee for Standardization. April 2013.

[19] EN 1015-11. Methods of test for mortar for masonry - Part 11: Determination of flexural and compressive strength of hardened mortar. 1999

[20] Lignola GP, Caggegi C, Ceroni F, De Santis S, Krajewski P, Lourenço PB, ... \& Zuccarino L. Performance assessment of basalt FRCM for retrofit applications on masonry. Compos Part BEng 2017; 128: 1-18.

[21] GOM GmbH. GOM Testing-Technical Documentation as of V8 SR1, Digital Image Correlation and Strain Computation Basics; GOM mbH: Braunschweig, Germany, 2016.

[22] De Santis S, de Felice G. Tensile behaviour of mortar-based composites for externally bonded reinforcement systems. Compos Part B-Eng 2015; 68: 401-413.

[23] Arboleda D, Carozzi FG, Nanni A, Poggi C. Testing procedures for the uniaxial tensile characterization of fabric-reinforced cementitious matrix composites. J Compos Constr 2015; 20(3): 04015063. 